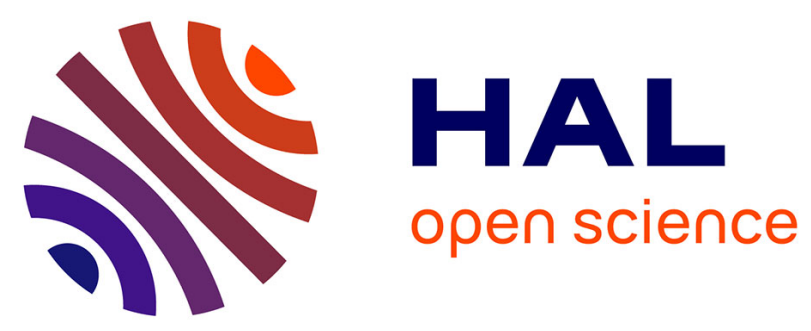

\title{
Mechanical characterization and modelling of Inconel 718 material behavior for machining process assessment
}

\author{
Ariane Iturbe, Eliane Giraud, Exabier Hormaetxe, Ainhara Garay, Guénaël
}

Germain, Koldo Ostolaza, Pedro José Arrazola

\section{To cite this version:}

Ariane Iturbe, Eliane Giraud, Exabier Hormaetxe, Ainhara Garay, Guénaël Germain, et al.. Mechanical characterization and modelling of Inconel 718 material behavior for machining process assessment. Materials Science and Engineering: A, 2017, 682, pp.441-453. 10.1016/j.msea.2016.11.054 . hal02283291

\section{HAL Id: hal-02283291 \\ https://hal.science/hal-02283291}

Submitted on 10 Sep 2019

HAL is a multi-disciplinary open access archive for the deposit and dissemination of scientific research documents, whether they are published or not. The documents may come from teaching and research institutions in France or abroad, or from public or private research centers.
L'archive ouverte pluridisciplinaire HAL, est destinée au dépôt et à la diffusion de documents scientifiques de niveau recherche, publiés ou non, émanant des établissements d'enseignement et de recherche français ou étrangers, des laboratoires publics ou privés. 


\title{
Mechanical characterization and modelling of Inconel 718 material behavior for machining process assessment
}

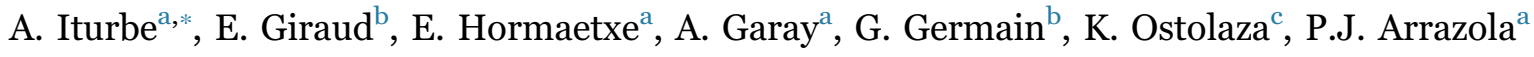 \\ a Faculty of Engineering, Mondragon University, Loramendi 4, Arrasate 20500, Spain \\ b Arts et Métiers ParisTech, CER Angers, Laboratoire LAMPA, 2 Bd du Ronceray, 49035 Angers Cedex 1, France \\ c ITP, Parque Tecnológico, Edificio 300, 48170 Zamudio, Bizkaia, Spain
}

\author{
Keywords: \\ Mechanical characterization \\ Nickel based superalloys \\ Thermomechanical processing \\ Inconel 718 \\ Modified Johnson-Cook model \\ Machining
}

\section{A B S T R A C T}

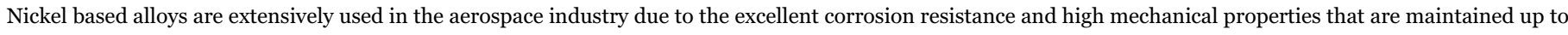

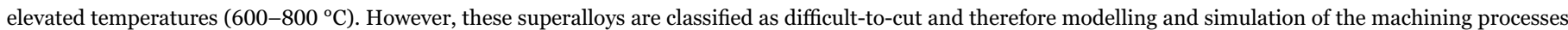

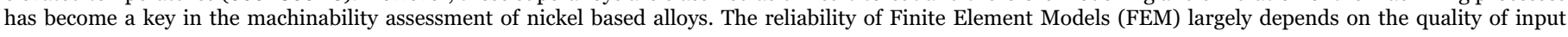
parameters, one of the most relevant being the constitutive material model representing work material behavior under high strain, strain rate and tempera-tures.

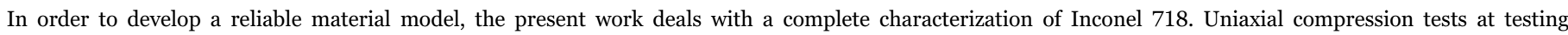

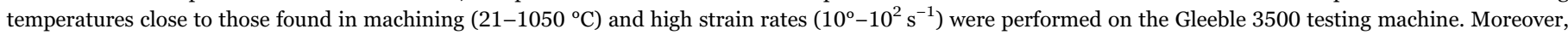

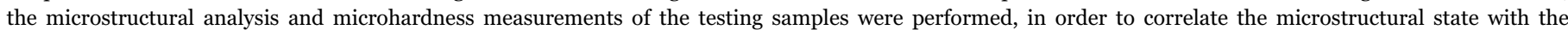

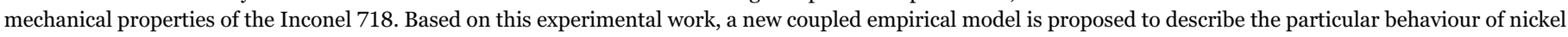

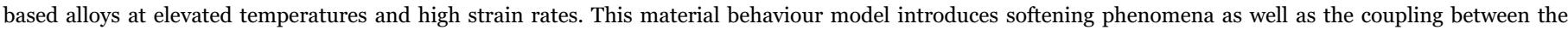
temperature and the strain rate known to occur experimentally, for machining FEM simulations with Inconel 718 superalloy.

\section{Introduction}

Nickel based alloys are extensively used in the aerospace industry due to their high corrosion and oxidation resistance, high strength and long creep life at elevated temperatures [1]. Inconel 718 is the most widely used nickel based alloy in the aerospace industry owing to the remarkable machinability and welding capability of this alloy in comparison with other superalloys [2]. Nickel based alloys, have a relatively high yield (700-1200 MPa) and tensile (900-1600 MPa) strength at room temperature [3]. The most remarkable property of nickel based alloys is that they maintain their mechanical properties within a wide range of temperatures (up to $600-800^{\circ} \mathrm{C}$ ) [1]. Therefore, these alloys are commonly used in the hot section of jet engines [4].

The mechanical properties of nickel based alloys greatly depend on the chemistry and the microstructural features of the superalloy, such as grain size, $\gamma^{\prime} / \gamma^{\prime \prime}$ size and distribution, carbide and boride size and content, and grain boundary morphology [5]. Inconel 718 exhibits a face-centred cubic (FCC) structure $\gamma$ matrix where the remaining phases reside. The main strengthening phase of this superalloy is the thermodynamically metastable phase $\gamma$ ”. After long term thermal exposure, this metastable phase may eventually transform into the stable phase $\delta\left(\mathrm{Ni}_{3} \mathrm{Nb}\right)$ at temperatures above $650{ }^{\circ} \mathrm{C}$, leading to a loss of properties of Inconel 718 above this temperature.

Concerning the machining performance, nickel based alloys are classified as difficult-to-cut. This is due to their special characteristics such as high strength at elevated temperatures, tendency to work hardening, poor thermal conductivity, the presence of hard abrasive carbides on their microstructure and the high chemical reactivity with the tool material and coatings $[6,7]$. These characteristics, lead to high power consumption and frequent tool changes that reduce productivity [8]. Considering the high workpiece material and experimentation cost, modelling and simulation of machining processes has become a key factor in the machinability assessment of nickel based alloys [9].

Nevertheless, the success and reliability of FEM modelling depends on the quality of input parameters such as the constitutive model representing the dynamic behavior of the workmaterial, the physical

\footnotetext{
* Corresponding author

E-mail address: aiturbei@mondragon.edu (A. Iturbe).
} 
and thermal properties of the workpiece and tool materials and toolchip contact conditions, such as friction and heat transfer coefficients [9]. Of this inputs, one of the most relevant to the model, is the constitutive material law representing workpiece material behavior under high strain, strain rate, and temperatures [10]. A major difficulty to describe the material behavior in the cutting process is the severe deformation that takes place at high temperatures and high strain rates in a very small area: the primary and secondary deformation zones [11]. Strain levels $\varepsilon(1-7)$, strain rate $\dot{\varepsilon}\left(0-10^{6} \mathrm{~s}^{-1}\right)$ and heating rates (close to $10^{6}{ }^{\circ} \mathrm{C} \mathrm{s}^{-1}$ ) can be encountered in metal cutting [11]. These unique features of deformation in metal cutting result in material behavior that is markedly different from that encountered in conventional material testing.

The identification of material constitutive laws for machining is generally carried out through direct experimental methods such as Split Hopkinson pressure bar (SHPB) tests [12], shear tests [13,14] and uniaxial compression tests at high temperatures and strain rates $[15,16]$.

Mechanical properties of Inconel 718 superalloy were mainly studied through uniaxial quasi-static compression tests at room and high temperatures and low strain rates $\left(\dot{\varepsilon} \leq 1 \mathrm{~s}^{-1}\right)$, which focused on the optimization of hot forming processes. Yuan and Liu characterized the mechanical properties of Inconel 718 in the temperature range between $900-1080^{\circ} \mathrm{C}$ and strain rates in the range of $10^{-3}$ $10^{\circ} \mathrm{s}^{-1}[17]$. More recently, Si et al. also utilised the hot compression technique to determine the mechanical properties of Inconel 718 in the temperature range between $900-1060{ }^{\circ} \mathrm{C}$ and strain rates in the range of $10^{-3}-0.5 \mathrm{~s}^{-1}[18]$. Wang et al. carried out hot compression tests on the Gleeble-1500 machine at temperatures in the range of 950$1100{ }^{\circ} \mathrm{C}$ and strain rates ranging from $10^{-3}$ to $10^{\circ} \mathrm{s}^{-1}$ to understand the dynamic recrystallization behaviour of Inconel 718 superalloy [19].

At closer conditions to those found in machining, Soo et al. carried out hot compression tests on Inconel 718 superaloy on the Gleeble 3500 thermo-mechanical simulator at temperatures in the range of 20$850{ }^{\circ} \mathrm{C}$ and strain rates ranging from $10^{\circ}$ to $10^{2} \mathrm{~s}^{-1}[16]$. Nevertheless, only strains up to $30 \%$ were reached on this study. Wang et al. utilised SHPB testing method to characterize Inconel 718 at higher strain rates, from 5000 to $11000 \mathrm{~s}^{-1}$, but on a narrower temperature range, from 500 to $800{ }^{\circ} \mathrm{C}$ [12]. Therefore, the material behaviour of Inconel 718 in conditions close to those found in machining has not been well addressed yet. Moreover, there is a lack of insight into interactions between strain, strain rate and temperature on this processing range.

The Johnson-Cook Material model [20] is the most widely used material constitutive law for simulating metal cutting processes. This empirical model (Table 1), considers isotropic hardening, strain rate hardening and thermal softening as three independent phenomena that can be isolated from each other (uncoupled). The equivalent flow stress $\sigma$ is calculated by multiplying these three phenomena: (i) $\left[A+B \varepsilon^{n}\right]$, isotropic hardening (ii) $\left[1+C \ln \left(\frac{\dot{\varepsilon}}{\dot{\varepsilon}_{0}}\right)\right]$ strain rate hardening and (iii) $\left[1-\left(\frac{T-T_{0}}{T_{m}-T_{0}}\right)^{m}\right]$ thermal softening where $\varepsilon$ is the equivalent plastic strain, $\dot{\varepsilon}$ is the plastic strain rate, $\dot{\varepsilon}_{0}$ is the reference equivalent plastic strain rate, $T$ is the workpiece temperature, $T_{m}$ is the material melting temperature and $T_{0}$ is the reference temperature. Regarding the model parameters that need to be calibrated for each material, $A$ is the yield strength of the material at the reference temperature and strain rate, $B$ is the strain hardening constant, $n$ is the strain-hardening exponent, $m$ is the thermal softening exponent and $C$ is the strain-rate sensitivity parameter.

The Johnson-Cook model parameters utilised in the literature as an input for FEM simulation with the Inconel 718 are summarized in Table 2. It is noteworthy that JC model parameters, mostly $A, C, n$, highly depend on the heat treatment. It is also appealing that various authors did not consider the thermal softening effect $(m=0)$.
Table 1

Different coupled material constitutive equations.

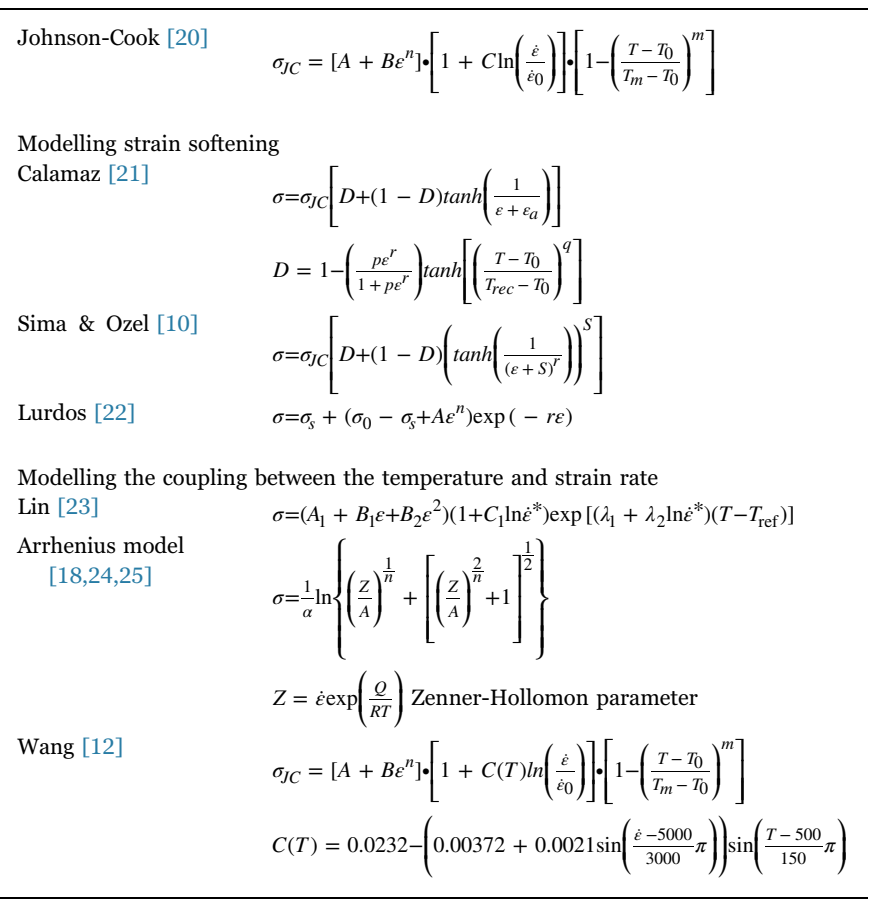

Even if Johnson-Cook Material model is the most widely used strength model in metal cutting simulations, this equation (Table 1) describes strain hardening as an increasing function that diverges to infinity with strain and does not consider strain-softening phenomena. However, it has been reported that softening phenomena is essential for the initiation and amplification of strain localization, which causes the formation of adiabatic shear bands in simulation of machining operations [21]. Thus, several authors have developed modified versions of the Johnson-Cook model in order to consider softening phenomena. Calamaz et al. proposed a TANH model that adds a new term to the conventional Johnson-Cook equation to take into account strain softening at elevated temperatures and strain rates [21]. In the TANH model (Table 1), flow softening is defined as a decreasing behavior in the flow stress with increasing strain beyond a critical strain value. The main advantage of this model is that the previously identified Johnson-Cook model parameters can be used $(A, B, C, n, m)$ to predict the flow behavior of the material. Nevertheless, five new parameters need to be identified in order to consider softening: $p, q, T_{\text {rec }}, r, \varepsilon_{0}$. Sima \& Ozel further modified the TANH material model by introducing an $S$ exponent to better control tangent hyperbolic (tanh) function for thermal softening [26]. Another approximation to consider flow softening was developed by Lurdos et al. [22] by adding a supplementary strain hardening term $A \varepsilon^{n}$ to the conventional Voce model [27]. The fundamental difference with the Johnson-Cook equation is the occurrence of steady state behavior in the Voce equation when compared to a divergent behavior of the strain hardening in Johnson-Cook equation. The strain rate and temperature sensitivity in this model are accounted by the variation of the five model parameters $\sigma_{s}, \sigma_{0}, r, A, n$ as a function of the temperature and the strain rate, where $\sigma_{0}$ is the initial yield strength and $\sigma_{s}$ the steady state stress.

Furthermore, Johnson-Cook model neglects the coupling between the strain, strain-rate and temperature known to occur experimentally [28]. For most metals, the strain rate sensitivity parameter is low near room temperature but increases with temperature [29]. On a sensitivity analysis of flow stress carried out by Fang, it was concluded that bellow the temperature of $500{ }^{\circ} \mathrm{C}$ Inconel 718 is not sensitive to strain rate hardening [30]. Therefore, several models have tried to describe the coupling of the effects of temperature and strain rate on the flow stress 
Table 2

The J-C Constitutive Model Parameters for Inconel 718 .

Source:Adapted from [10].

\begin{tabular}{|c|c|c|c|c|c|c|c|}
\hline Reference & A (MPa) & B (MPa) & C (-) & n (-) & m (-) & $\dot{\varepsilon}\left(\mathrm{s}^{-1}\right)$ & Heat treat. \\
\hline [37] & 450 & 1798 & 0.0312 & 0.9143 & 0 & 1.0 & Annealed \\
\hline [37] & 1350 & 1139 & 0.0134 & 0.6522 & 0 & 1.0 & Aged \\
\hline [38] & 450 & 1700 & 0.017 & 0.65 & 1.3 & 0.001 & Annealed \\
\hline \multicolumn{8}{|l|}{ [39] } \\
\hline \multicolumn{8}{|l|}{ [40] } \\
\hline [41] & 1241 & 622 & 0.0134 & 0.6522 & 0 & 1.0 & Aged \\
\hline [42] & 1241 & 622 & 0.0134 & 0.6522 & 1.3 & 1.0 & Aged \\
\hline
\end{tabular}

(Table 1). Lin et al. modified Johnson-Cook model, to consider the coupled effects of temperature and strain rate on the flow stress behaviour of high-strength steels [23]. In this modified JohnsonCook model six constants need to be calibrated for each material $A_{1}, \quad B_{1}, \quad B_{2}, \quad C_{1}, \lambda_{1}, \quad \lambda_{2}$. This modified Johnson-Cook model is said to greatly improve the prediction accuracy of conventional Johnson-Cook model at low strain rates $\left(<1 \mathrm{~s}^{-1}\right)$ in the case of steels $[23,24]$ and aluminum alloys [25]. These studies, concluded that further improvements over the conventional and modified JohnsonCook model can be obtained through the hyperbolic sine-typed Arrhenius model (Table 1). In the case of nickel based alloys, Si et al. (2015) also utilised the Arrhenius model to describe the flow stress behaviour of Inconel 718 at high temperatures $\left(900-1060{ }^{\circ} \mathrm{C}\right)$ and low strain rates $\left(10^{-3}-0.5 \mathrm{~s}^{-1}\right)$ for metal forming processes [18]. At closer conditions to machining Wang et al. (2013) proposed a modified Johnson-Cook model where the strain rate softening effect was considered by means of the strain-rate sensitivity parameter, $C$, written as a function of the temperature $C=\mathrm{f}(T)$ (Table 1). This modified Johnson-Cook model, was based on dynamic behaviour data obtained for Inconel 718 superalloy, through SHPB tests carried out at high strain rates $5000-11000 \mathrm{~s}^{-1}$ and temperatures in the range of 500$800^{\circ} \mathrm{C}[12]$.

In this context, the present work deals with a complete mechanical characterization of Inconel 718 in conditions close to those found in machining. Uniaxial compression tests at high testing temperatures and strain rates were performed on the Gleeble 3500 thermo-mechanical testing machine. This experimental work was further completed with the microstructural analysis and microhardness measurements of the testing samples, to fully assess material behaviour. Based on this experimental work, a new constitutive material model is proposed to describe the behaviour of Inconel 718 at high temperatures and high strain rates, for machining FEM simulations.

\section{Experimental procedure}

Uniaxial compression tests at temperatures in the range of 21$1050{ }^{\circ} \mathrm{C}$ and strain rates ranging from $10^{\circ}$ to $10^{2} \mathrm{~s}^{-1}$ were performed on the Gleeble 3500 thermo-mechanical testing machine. A schematic representation of the compression configuration is shown in Fig. 1.

During the Gleeble tests, the specimens were positioned between two tungsten carbide anvils that allowed the current passage and maintained the specimen at a uniform temperature during the compression cycle. Thin graphite foils were placed on the two opposite sides of the specimen to reduce friction at the specimen/anvil interface and ensure a more uniform deformation, which reduced barrelling. The tests were performed in a primary vacuum chamber to avoid oxidation at high temperatures. Temperature during the tests was measured by K-type thermocouples, which were resistance welded to the centre of the specimen. The testing samples were heated up to the testing temperature at a rate of $10^{\circ} \mathrm{C} / \mathrm{s}$. The temperature was then held constant for $20 \mathrm{~s}$ so as to ensure temperature homogenization throughout the specimen. Next, the material was deformed at a constant strain rate and the specimen was cooled in a vacuum.
Strain during the tests was determined from the displacement measured by a quartz longitudinal extensometer placed on the jaws (Fig. 1). The displacement value given by the extensometer included the elastic deformation of the jaws and the hot anvils, in addition to the displacement of the testing specimen. Therefore, the stress-strain curves were corrected to take into account just the specimen displacement. Moreover, for the tests carried out at high temperatures and strain rates, the curves were smoothed in OriginPro8 software, in order to reduce the shock effect on the curves.

Two testing configurations were utilised on these compression tests. The tests at low and medium strain rates $\left(\dot{\varepsilon} \leq \mathrm{s}^{-1}\right)$ were performed with the coupled method, while the tests at high strain rates $\left(100 \geq \dot{\varepsilon}>1 \mathrm{~s}^{-1}\right)$ were accomplished with the uncoupled method. A more detailed description of both testing methods is given by Hor et al. [16].

Cylindrical shaped Inconel 718 specimens having a diameter of $6 \mathrm{~mm}$ and $9 \mathrm{~mm}$ length were used in the compression tests. These specimens were designed according to the ASTM E9 - 09 and ASTM E209 - 00(2010) Standards. Tested Inconel 718 was Solution Heat Treated $\left(980^{\circ} \mathrm{C}\right)$ followed by a Double Stage Aging $\left(720^{\circ} \mathrm{C}\right.$ and $620^{\circ} \mathrm{C}$ ). The microstructure of the Inconel 718 used in the compression tests is shown in Fig. 2.

The aim of these mechanical characterization tests is to extract a material constitutive model that takes into account the influence of temperature and strain rate for machining FEM simulations. Therefore, the experimental tests were carried out at testing temperatures $\left(21-1050^{\circ} \mathrm{C}\right)$ commonly found in machining and strain rates as high as possible (up to $10^{2} \mathrm{~s}^{-1}$ ). The experimental plan for the compression tests with Inconel 718 superalloy is shown in Table 3. Each test was conducted twice to determine the uncertainty.

After performing the experimental tests, the samples were further prepared for microstructural observations following the subsequent procedure: Specimens were cut longitudinally on the precision cutting machine Strues Accutom-5; afterwards, they were mounted in cold utilising a polymeric resin; and lastly, they were polished and etched. The microstructural analysis was performed in the Axio Imager 2 Zeiss light microscope. Lastly, microhardness measurements were carried out on the Innovatest Nova 330/360 IMP Vickers hardness testing machine, subjected to a load of $\mathrm{m}=10 \mathrm{kgf}$.

\section{Results and discussion}

\subsection{Flow stress-strain behaviour}

As a general trend, flow stress of the Inconel 718 increased with increasing the strain rate and decreasing the temperature. The stressstrain curves of the Inconel 718 over a wide range of temperatures (21$1050{ }^{\circ} \mathrm{C}$ ) at a strain rate of $1 \mathrm{~s}^{-1}$ are shown in Fig. 3. It can be seen that for a given strain rate, as the temperature rose the strength of the material decreased.

Nevertheless, this thermal softening effect was not very pronounced in the Inconel 718 until the critical temperature of $700{ }^{\circ} \mathrm{C}$ was exceeded (Fig. 4). The mechanical properties of the Inconel 718 decreased on a $20 \%$ in the temperature range between 21 and $700{ }^{\circ} \mathrm{C}$ (Fig. 3). Soo 


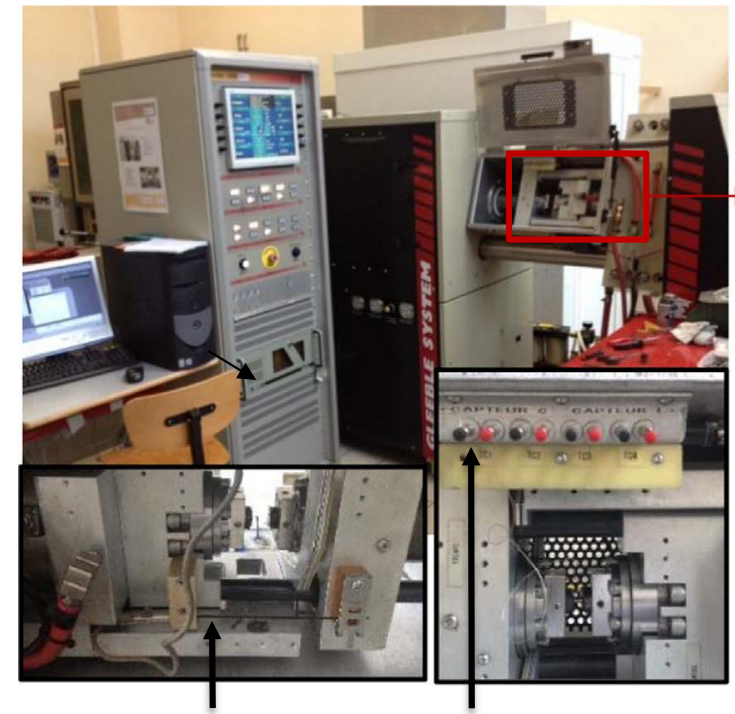

Strain measurement Temperature measurement

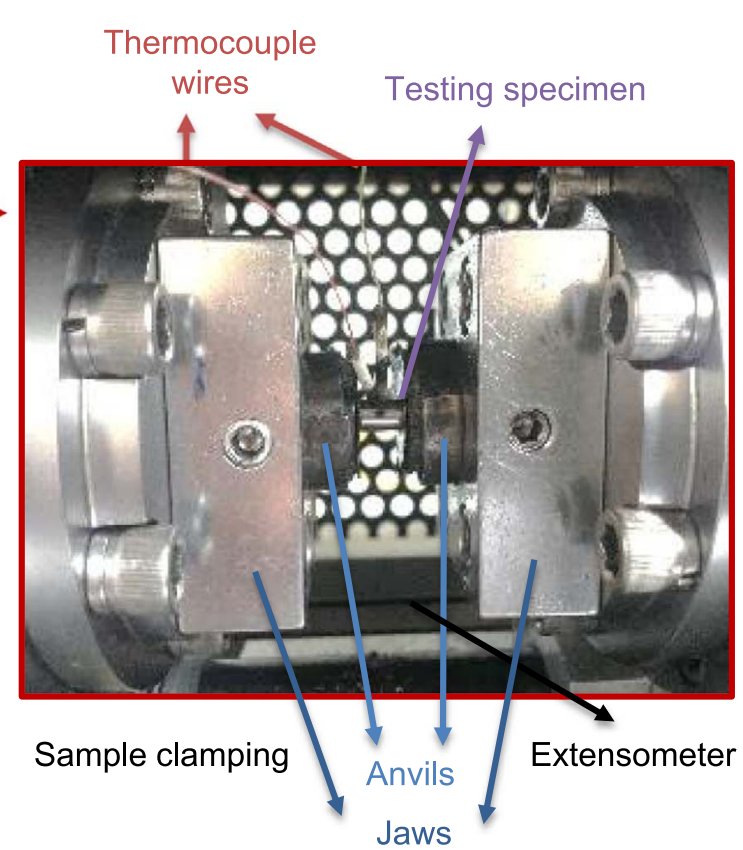

Jaws

Fig. 1. Experimental set-up of the compression tests.

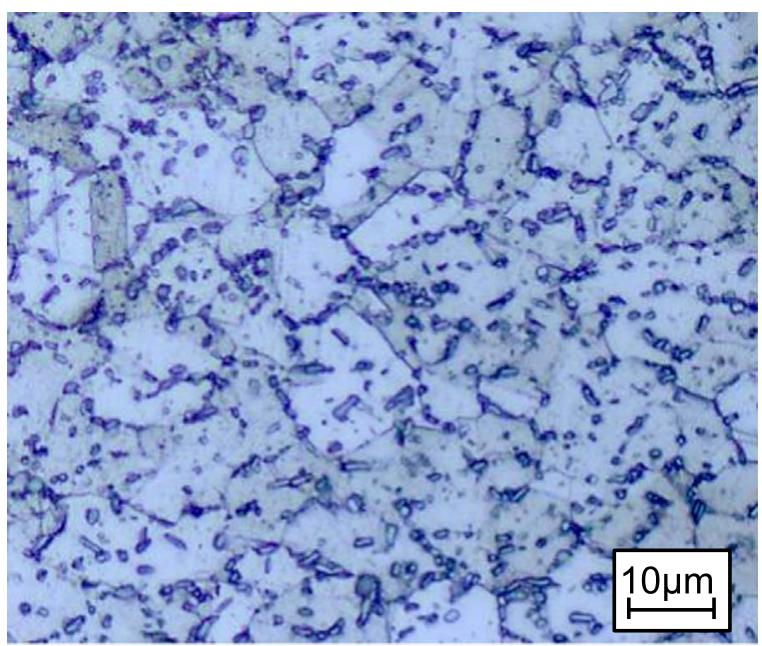

Fig. 2. Microstructure of the tested Inconel 718.

Table 3

Experimental plan of the mechanical characterization tests carried out with Inconel 718.

\begin{tabular}{|c|c|c|c|c|c|c|c|c|}
\hline $10^{\circ} \mathrm{C} / \mathrm{s}$ & \multicolumn{2}{|c|}{0.01} & \multicolumn{2}{|c|}{1} & \multicolumn{2}{|c|}{10} & \multicolumn{2}{|c|}{100} \\
\hline$\dot{\varepsilon}\left(\mathrm{s}^{-1}\right)$ & \multicolumn{2}{|c|}{0.01} & $\mathrm{R} 1$ & $\mathrm{R} 2$ & $\mathrm{R} 1$ & $\mathrm{R} 2$ & $\mathrm{R} 1$ & $\mathrm{R} 2$ \\
\hline $\mathrm{T}\left({ }^{\circ} \mathrm{C}\right)$ & $\mathrm{R} 1$ & $\mathrm{R} 2$ & $\mathrm{R} 1$ & \\
\hline 21 & & & & & & & & \\
\hline 600 & & & & & & & & \\
\hline 650 & & & & & & & & \\
\hline 700 & & & & & & & & \\
\hline 760 & & & & & & & & \\
\hline 800 & & & & & & & & \\
\hline 900 & & & & & & & & \\
\hline 1050 & & & & & & & & \\
\hline
\end{tabular}

et al. (2004) reported similar results as they observed that it was not until the temperature exceeded approximately $700{ }^{\circ} \mathrm{C}$ that the stress in Inconel 718 dropped drastically [16].
Inconel 718

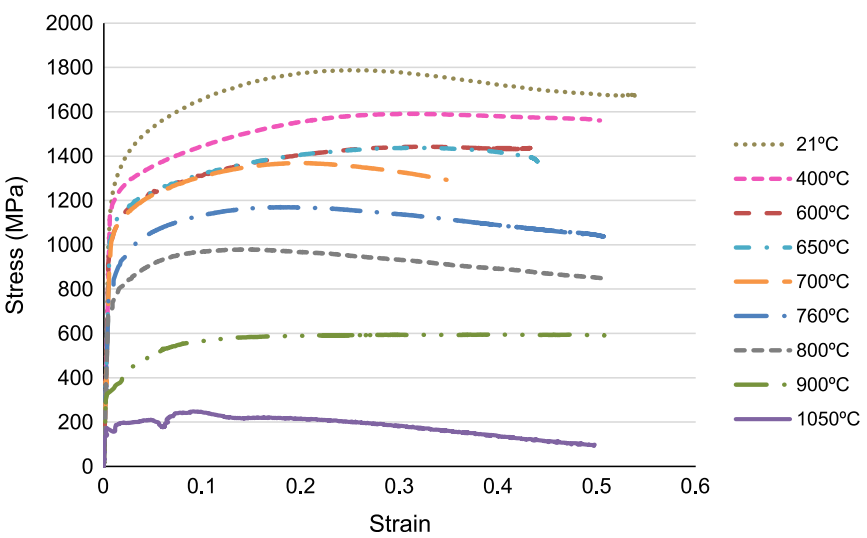

Fig. 3. Influence of temperature on the flow behaviour of the Inconel 718 when compressed at a strain rate of $1 \mathrm{~s}^{-1}$.

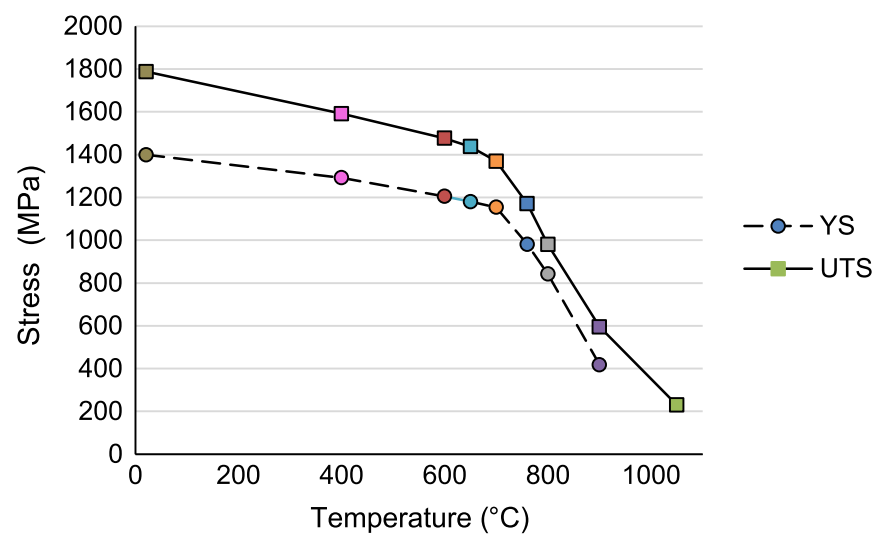

Fig. 4. Influence of temperature on the Yield Strength (YS) and Ultimate Tensile Strength (UTS) of the Inconel 718 when compressed at a strain rate of $1 \mathrm{~s}^{-1}$.

The decrease in the flow stress as a result of the temperature rise was observed at the different strain rates tested. Therefore, the thermal softening effect could be considered as an independent factor that does not show coupling with the strain rate, for the material constitutive model. 

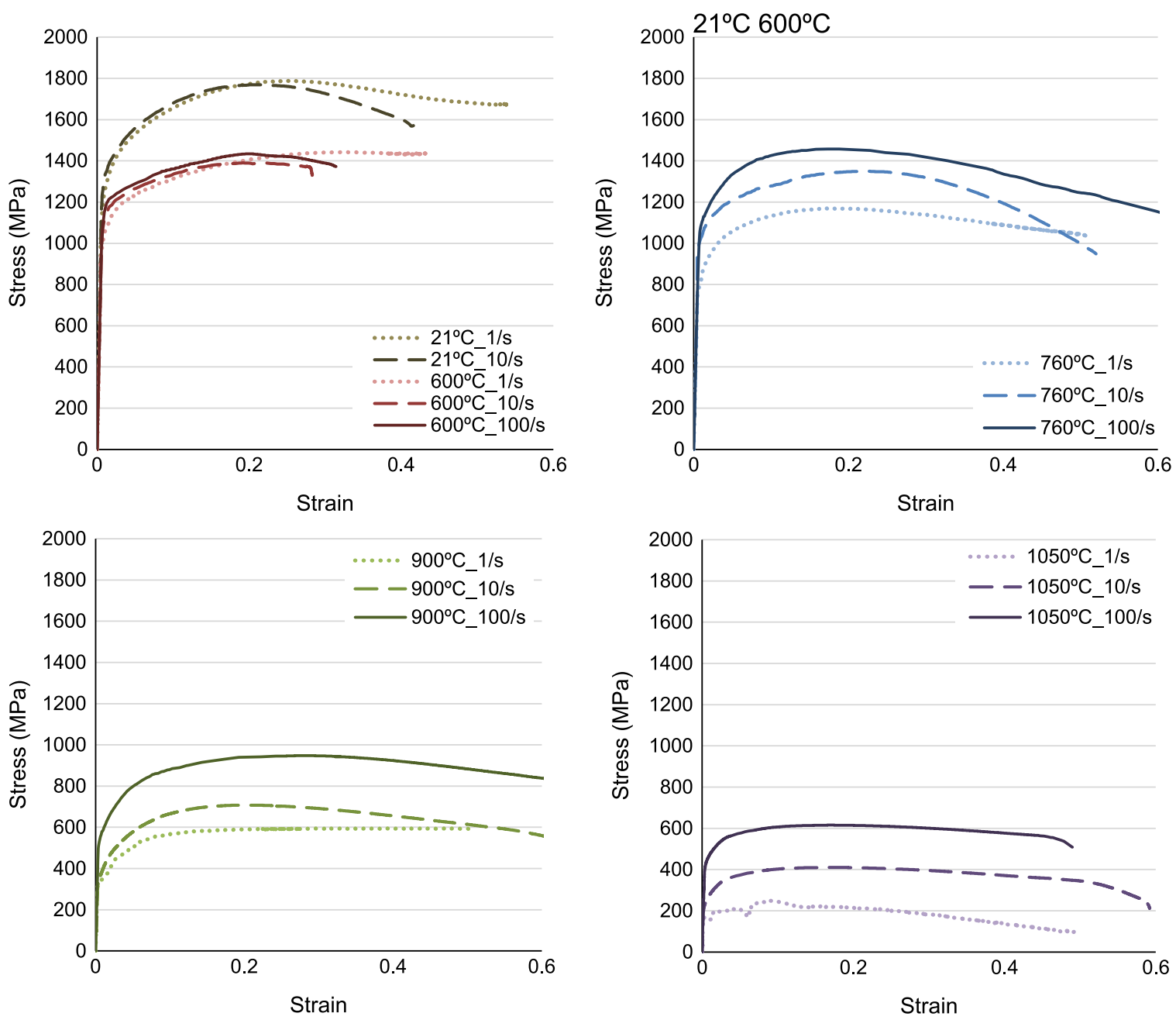

Fig. 5. Influence of temperature and strain rate on the flow behaviour of the Inconel 718 .

Moreover, a change in the shape of the curves was observed with the temperature rise (Fig. 3). The slope of the flow-stress curves can be either positive, indicating work hardening or negative, indicating softening. With respect to this competition between work hardening and softening, two deformation domains were distinguished as a function of the temperature. At the low temperature range (< $700{ }^{\circ} \mathrm{C}$ ) were the mechanical properties still remained high, work hardening was the main phenomena observed followed by the shear failure of the samples at strain levels in the range of 0.3-0.45 (Fig. 3, Fig. 5). Increasing the strain rate led to the appearance of softening (Fig. 5). This phenomenon can be attributed to the self-heating of the samples at high heating rates. During dynamic tests $\left(>1 \mathrm{~s}^{-1}\right)$, the plastic power is converted into heat which cannot be evacuated in such a short testing time [28]. This phenomenon causes the flow stress to decrease at the end of the deformation process.

Above $700{ }^{\circ} \mathrm{C}$ on the other hand, the phenomenon that dominated was softening. The behaviour of the material in this domain, could be described by a first interval of strain hardening up to the strain level of $\sim 0.15$ followed by a flow softening domain where the stress decreased with further increasing strain (Fig. 5). The initial rapid rise in stress is associated with an increase in the dislocation density [17]. Softening on the other hand, is usually attributed to the dislocation mobility that is perturbed by thermally activated phenomena such as dynamic recrystallization once a critical strain is achieved [31]. Nevertheless, this statement should be confirmed through microstructural observations on the following section.

Stress-strain curves of the Inconel 718 at strain rates varying from $10^{\circ}$ to $10^{2} \mathrm{~s}^{-1}$ at a wide range of temperatures $\left(21-1050^{\circ} \mathrm{C}\right)$ are shown in Fig. 5. It can be seen that for a given temperature, the strength of the material increased with increasing the strain rate. When the strain rate increases, the dislocation density increases and dislocation pileup happens, resulting on the hardening of the superalloy [19]. At the low temperature domain $\left(<700{ }^{\circ} \mathrm{C}\right)$, the influence of the strain rate on the material strength was practically negligible in the strain rate interval of $10^{\circ}-10^{2} \mathrm{~s}^{-1}$ but as the temperature increased, the material behaved in a more viscous manner (Fig. 5). The stress in the high temperature domain $\left(>700^{\circ} \mathrm{C}\right.$ ) was sensitive to the strain rate, being the strain rate hardening more pronounced as the temperature increased. From these tests, it is concluded that the influence of strain rate on flow stress of the Inconel 718 is temperature dependent. Therefore, the coupling between the temperature and the strain rate should be taken into account when proposing a material behaviour model for Inconel 718 superalloy.

\subsection{Microstructural observations}

To extract additional information concerning microstructural changes, the metallurgy of the deformed specimens was analysed through optical microscopy. The evolution of the microstructure with the temperature rise in Inconel 718 is shown in Fig. 6 at the strain rate of $1 \mathrm{~s}^{-1}$. Up to the temperature of $700{ }^{\circ} \mathrm{C}$, the grains in the centre of the specimen were heavily deformed and evidence of slip bands was found inside the grains (Fig. 6). Slip bands are usually related to strain hardening phenomena, which was the main deformation mechanism observed in the curves below the temperature of $700{ }^{\circ} \mathrm{C}$ (Fig. 3). The appearance of these strain marks was also reported when investigating 


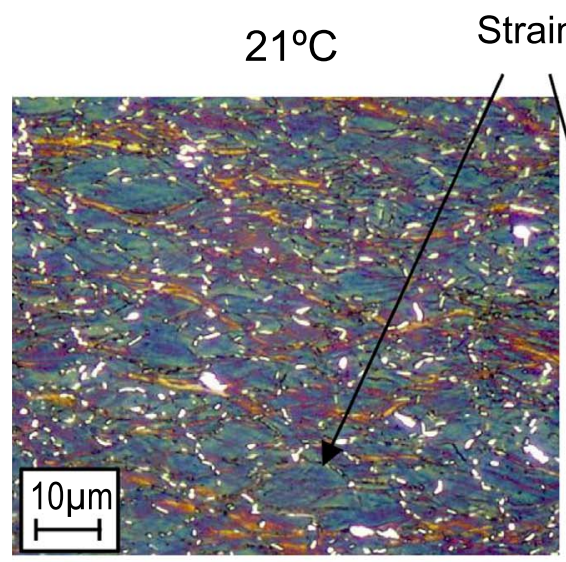

$760^{\circ} \mathrm{C}$
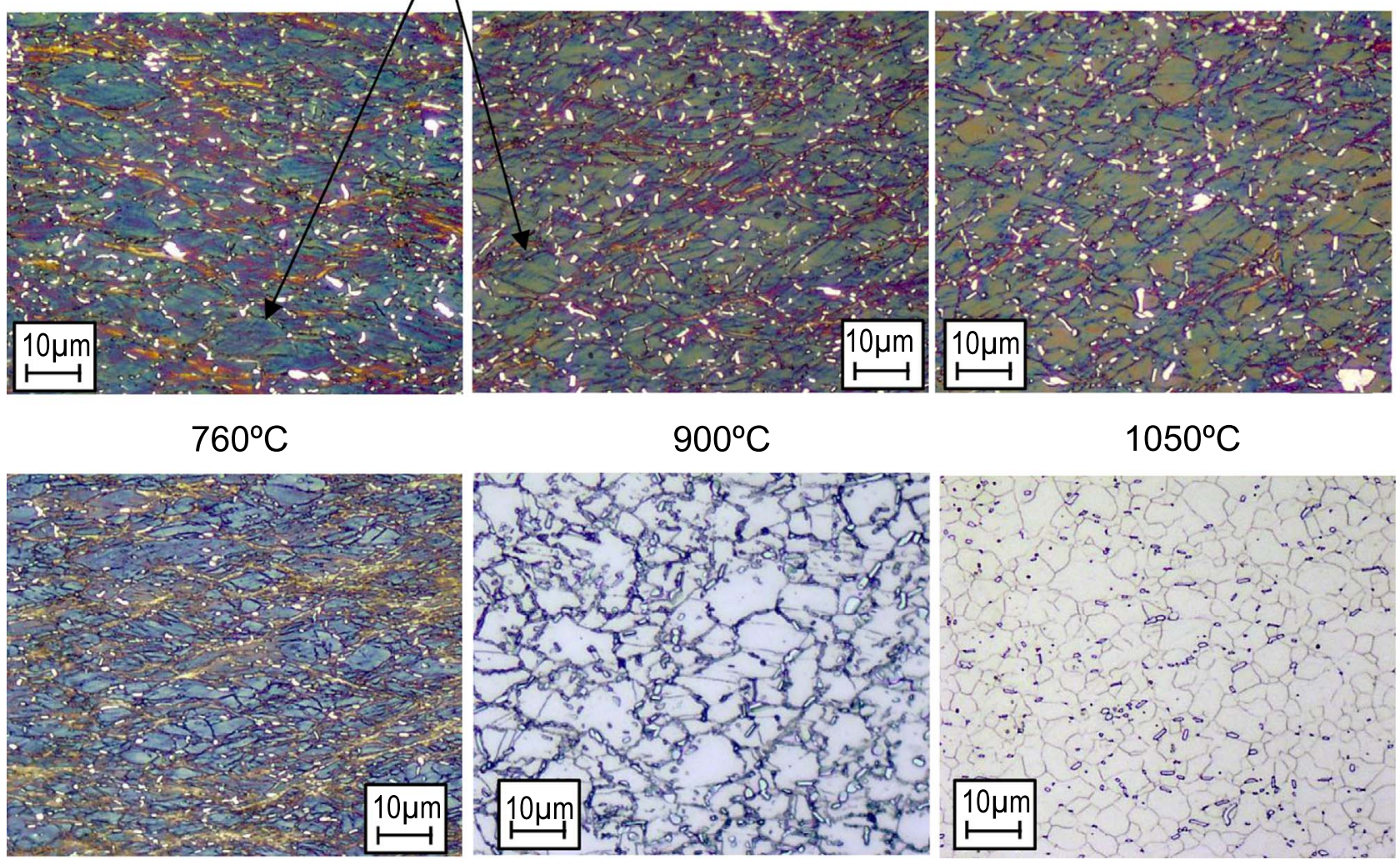

Fig. 6. Influence of the temperature in the microstructure of the tested Inconel 718 at a strain rate of $1 \mathrm{~s}^{-1}$ and strain levels in the range of $0.42-0.5$.

the strain hardening mechanisms of aged AEREX350 superalloy during room temperature compression testing [32].

At the compression tests performed in the temperature range between $21-700^{\circ} \mathrm{C}$, specimen failure occurred by shear fracture at $45^{\circ}$ to the compression axis at strain levels in the range of $0.3-0.45$. At the temperatures of 760 and $800{ }^{\circ} \mathrm{C}$, the specimens ended also sheared but reached higher strain levels $\sim 0.6$ (Fig. 5). Evidence of this shearing was observed by optical microscopy, with the apparition of localised shear bands (Fig. 6). Therefore, the strain softening observed in the strain-stress curves at the temperatures of 760 and $800^{\circ} \mathrm{C}$ (Fig. 3,
Fig. 7) would be related to the strain localization in the samples rather than the dynamic recrystallization. No evidence of recrystallization was observed microscopically at the temperature range between 760 and $800{ }^{\circ} \mathrm{C}$ in the tested Inconel 718 (Fig. 6).

Above the temperature of $900{ }^{\circ} \mathrm{C}$ on the other hand, the shape of flow stress curves in Inconel 718 indicated that the softening was promoted by dynamic recovery followed by dynamic recrystallization (Fig. 7). Steady state flow observed at the temperature of $900{ }^{\circ} \mathrm{C}$, would be related to dynamic recovery (DRV) while the flow softening observed at the temperature of $1050{ }^{\circ} \mathrm{C}$ would be related to dynamic

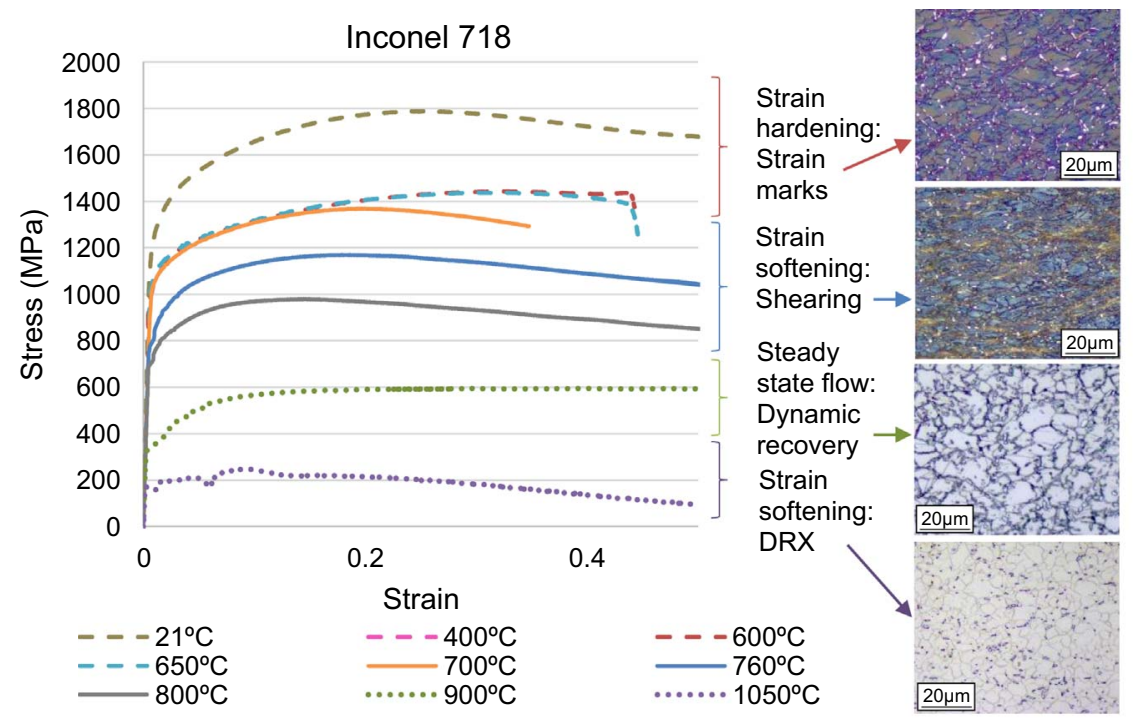

Fig. 7. Relationship between the shape of the strain-stress curves and the microstructure of Inconel 718 at different temperatures $\left(21-1050{ }^{\circ} \mathrm{C}\right)$ and a given strain rate of $1 \mathrm{~s}^{-1}$. 


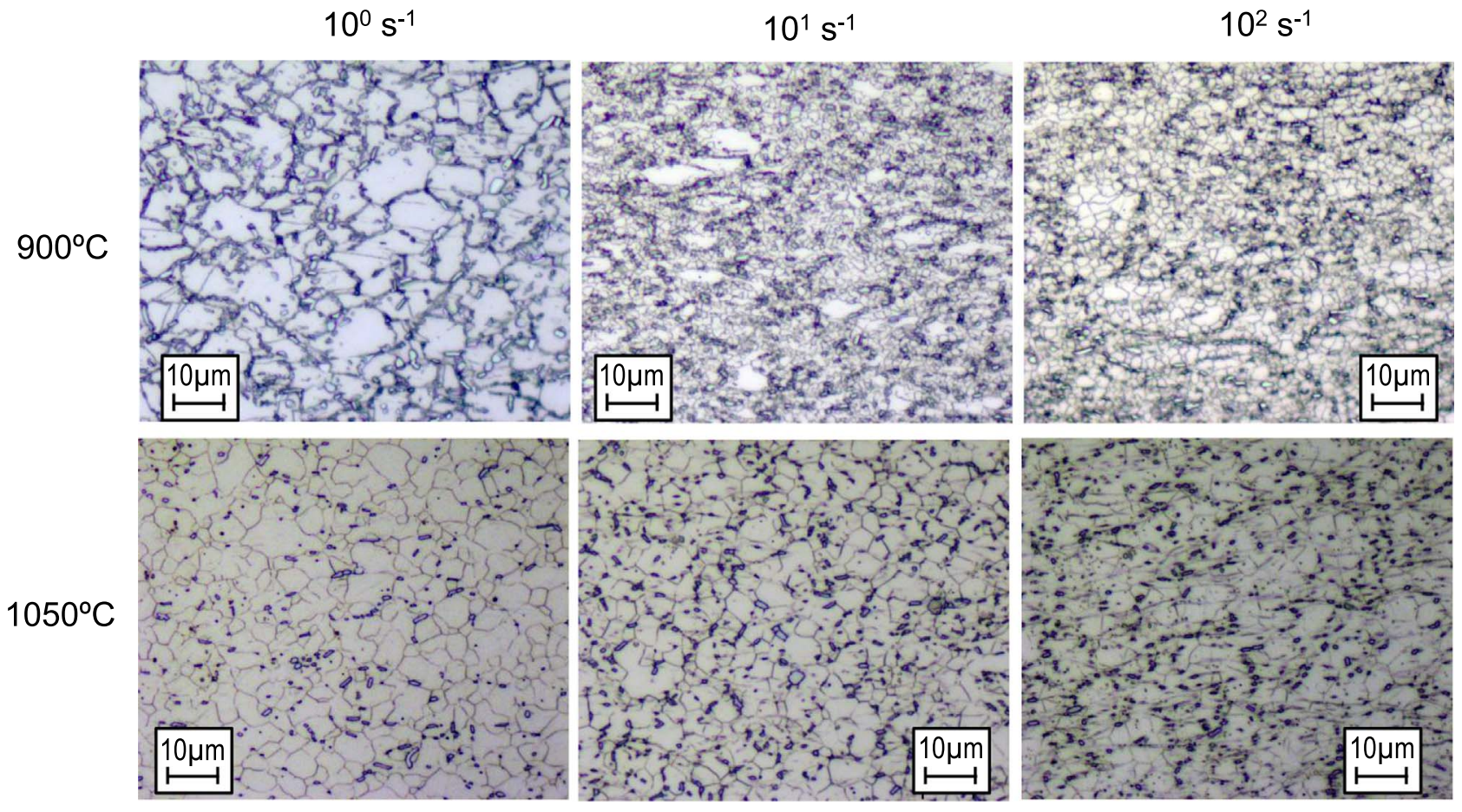

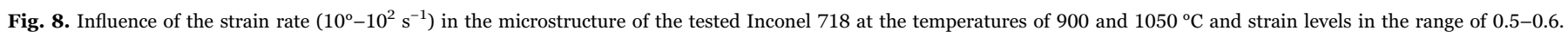

recrystallization (DRX) [33]. From Fig. 8 it is clear that the nucleation and growth of new grains occurred during deformation at the temperatures of $900{ }^{\circ} \mathrm{C}$ and $1050{ }^{\circ} \mathrm{C}$. Moreover, it can be seen (Fig. 8) that the increase in the strain rate activated dynamic recrystallization at high testing temperatures. At the temperature of $900{ }^{\circ} \mathrm{C}$, strained and recovered grains were observed at the strain rate of $1 \mathrm{~s}^{-1}$, while a partially recrystallized structure was observed with further increasing the strain rate $\dot{\varepsilon}=10^{1} ; 10^{2} \mathrm{~s}^{-1}$ (Fig. 8). At the temperature of $1050{ }^{\circ} \mathrm{C}$ on the other hand, the grains were fully recrystallized (Fig. 8) at the three tested strain rates $\dot{\varepsilon}=10^{\circ} ; 10^{1}$, $10^{2} \mathrm{~s}^{-1}$. These results are consistent with those obtained by Yuan et al.(2005) were they observed that at $900{ }^{\circ} \mathrm{C}$ and strain rate of $10^{\circ} \mathrm{s}^{-1}$ only dynamic recovery took place while at $1050{ }^{\circ} \mathrm{C}$ and the same strain rate, partially recrystallized grains should be attended [17].

Evolution of delta phase quantity with temperature increase in the deformed samples is shown in Fig. 9. As expected from the phase fraction diagrams for Inconel 718 predicted by JMatPro software, delta phase fraction remained almost constant up to the temperature of $900{ }^{\circ} \mathrm{C} . \delta$ solvus temperature in Inconel 718 is in the range of $1000-$ $1020^{\circ} \mathrm{C}[34,35]$. Therefore, at the temperature of $1050{ }^{\circ} \mathrm{C}$ delta phase percentage was found to be negligible. Moreover, these microstructural observations also confirm the occurrence of dynamic recrystallization in Inconel 718 at the temperature of $1050{ }^{\circ} \mathrm{C}$.

Besides this microstructural analysis, it is well known that the most significant strengthening mechanism in nickel based alloys is precipitation strengthening from $\gamma^{\prime}$ and $\gamma$ ". The mechanical properties of the superalloys are strongly related to the size and distribution of their main strengthening phases. Particularly, the yield stress of superalloys correlates very strongly with the sum of the fractions of their main strengthening phases $\gamma^{\prime}$ and/or $\gamma^{\prime \prime}[1]$. However, it is impossible to detect these strengthening phases by optical microscopy as their size is smaller than a micrometre $(0,1-0.9 \mu \mathrm{m})$. These phases are usually detected by Transmission Electron Microscopy (TEM) [36]. Therefore, as a first approximation, the evolution of the $\gamma$ ' and $\gamma$ " phase content as a function of the temperature was made through the Inconel 718 phase diagram provided by JMatPro software (Fig. 10). $\gamma^{\prime}$ and $\gamma^{\prime}$ 'phase fraction in Inconel 718 as a function of the temperature are summarized in Table 4. These results are also consistent with the precipitation phase content reported by Kennedy (2005) for the Inconel 718: $\gamma$, phase solvus temperature was found to be $909^{\circ} \mathrm{C}$ and $\gamma$ " phase solvus was established at $946{ }^{\circ} \mathrm{C}[34,35]$.

Delta phase fraction as a function of the temperature was determined from the microstructural observations carried out in the optical microscope (Fig. 9). This experimental estimation $\left(\delta_{\exp }\right.$, Table 4$)$, was performed utilising ImageJ software as shown in Fig. 11. Additionally, delta phase fraction as a function of the temperature was determined from the Inconel 718 phase diagram $\left(\delta_{\text {diagr. }}\right.$. Table 4$)$ provided by JMatPro software (Fig. 10). Delta phase fraction determined experimentally $\left(\delta_{\exp }\right.$, Fig. 11) was slightly higher than the delta phase fraction given by the JMatPro phase diagrams $\left(\delta_{\text {diagr. }}\right.$, Fig. 10$)$.

In Fig. 12 it can be seen that the mechanical properties of the Inconel 718, strongly depend on the phase fraction of its main strengthening phases, $\gamma^{\prime}$ and $\gamma^{\prime \prime}$, as a function of the temperature and not on the quantity of delta phase. These results are in good agreement from what expected from the superalloy basis [1].

To extract additional information concerning microstructural changes, microhardness measurements were conducted at the centre of the specimen. In line with the results obtained in the microstructural analysis and the flow stress curves, two domains were distinguished on the microhardness measurements as a function of the temperature (Fig. 13): At the low temperature range $\leq 700{ }^{\circ} \mathrm{C}$, hardness was found to be higher than the initial base material hardness, denoting strain hardening. Above the temperature of $700{ }^{\circ} \mathrm{C}$ on the other hand, the microhardness gradually decreased with the temperature increase and it was lower than the initial hardness of the material (the ratio hardness/initial hardness is less than 1). This denotes that the softening effect was more important than the hardening in this domain. This is confirmed by the shape of the flow stress curves obtained above the temperature of $700{ }^{\circ} \mathrm{C}$ (Fig. 3, Fig. 5).

\section{Material behaviour model proposal}

Success and reliability of FEM modelling largely depends on the constitutive model representing material behavior under high strain, strain rate and temperatures. Accordingly, a material model describing the behavior of the Inconel 718 in conditions close to those found in 

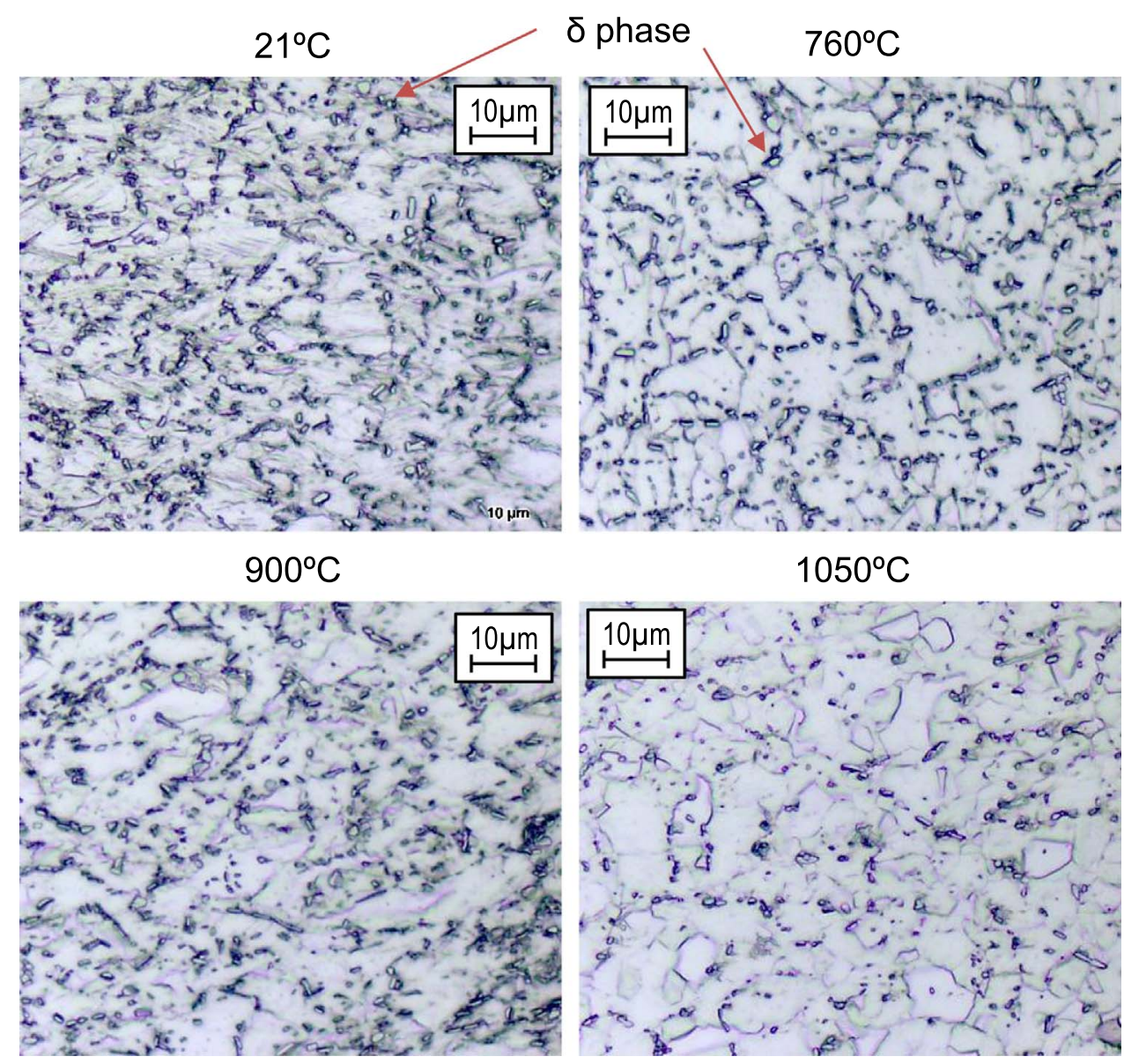

Fig. 9. Influence of the temperature in the delta phase fraction on Inconel 718 at the strain rate of $1 \mathrm{~s}^{-1}$ and strain levels in the range of $0.42-0.5$.

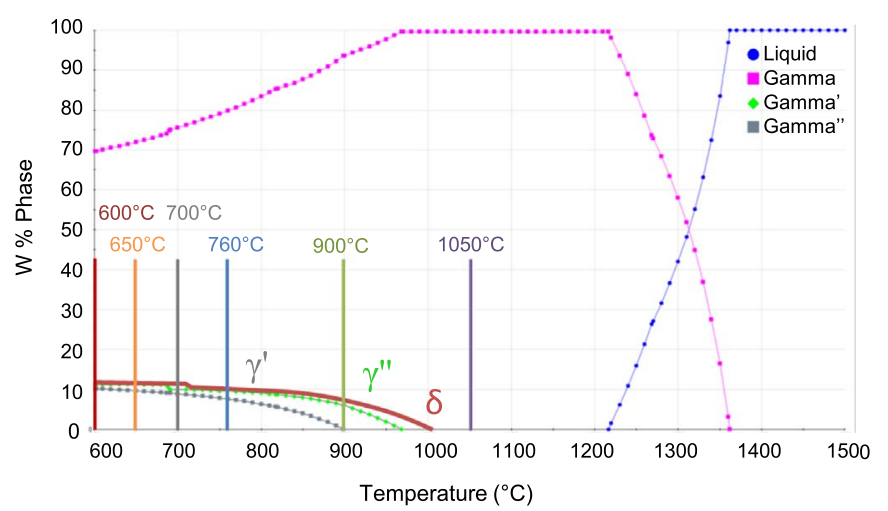

Fig. 10. Inconel 718 phase fraction diagram provided by JMatPro software.

Table 4

Phase fraction of the secondary phases in Inconel 718.

\begin{tabular}{lllllll}
\hline wt\% & $\mathbf{6 0 0}^{\circ} \mathbf{C}$ & $\mathbf{6 5 0}^{\circ} \mathbf{C}$ & $\mathbf{7 0 0}^{\circ} \mathbf{C}$ & $\mathbf{7 6 0}^{\circ} \mathbf{C}$ & $\mathbf{9 0 0}^{\circ} \mathbf{C}$ & $\mathbf{1 0 5 0}^{\circ} \mathbf{C}$ \\
\hline$\gamma^{\prime}$ & 10 & 9 & 8.5 & 7 & 0 & 0 \\
$\gamma^{\prime \prime}$ & 11 & 11 & 10 & 9.5 & 6 & 0 \\
$\delta_{\text {diagr. }}$ & 12.3 & 12 & 11.6 & 10.5 & 8 & 0 \\
$\delta_{\text {exp. }}$ & 16.2 & 16.7 & 17.2 & 17.2 & 17.2 & 6.2 \\
\hline
\end{tabular}

machining is proposed in this section. This model is based on the experimental data obtained on the mechanical characterization tests presented in the previous section.

Johnson-Cook constitutive model [20] is the most frequently used model for simulating metal cutting processes. Therefore, the first approach to describe the material behavior of the Inconel 718 was done through the conventional Johnson-Cook model (Table 1). Hereafter, Johnson-Cook models strain hardening, thermal softening and strain rate hardening terms have been further modified to better represent the particular behaviour of nickel based alloys.

For the Johnson-Cook model parameter identification (Table 1), $21{ }^{\circ} \mathrm{C}$ was taken as the reference temperature and $1 \mathrm{~s}^{-1}$ as the reference strain rate. The conventional JC model parameters determined from the experimental data in Inconel 718 are summarized in Table 5.

\subsection{Strain hardening-softening}

The comparison between the measured and predicted results by the conventional Johnson-Cook model on Inconel 718 are shown in Fig. 14. Johnson-Cook material model, considers isotropic hardening (1) and therefore, this model could be successfully used to predict the strain hardening behaviour of the Inconel 718 up to the Ultimate Tensile Stress at a strain level of $\sim 0.26$. From this strain level on, JC model highly overestimates material stress as it diverges to infinity with strain (Fig. 14).

$\sigma_{\varepsilon(\mathrm{JC})}=\left[A+B \varepsilon^{n}\right]$

Based on the experimental results (Fig. 3), a material model to predict the flow behaviour of the Inconel 718 should consider strain hardening up to a strain level of $\sim 0.26$ followed by a strain softening range where stress decreases with further increasing strain. Several constitutive models (Table 1) found in the literature were tested to represent the strain hardening as well as the strain softening observed experimentally with Inconel 718 superalloy. The prediction offered by common material constitutive models on the strain hardening/softening behaviour (Table 1) were compared against an experimental 


\section{$\delta$ phase}
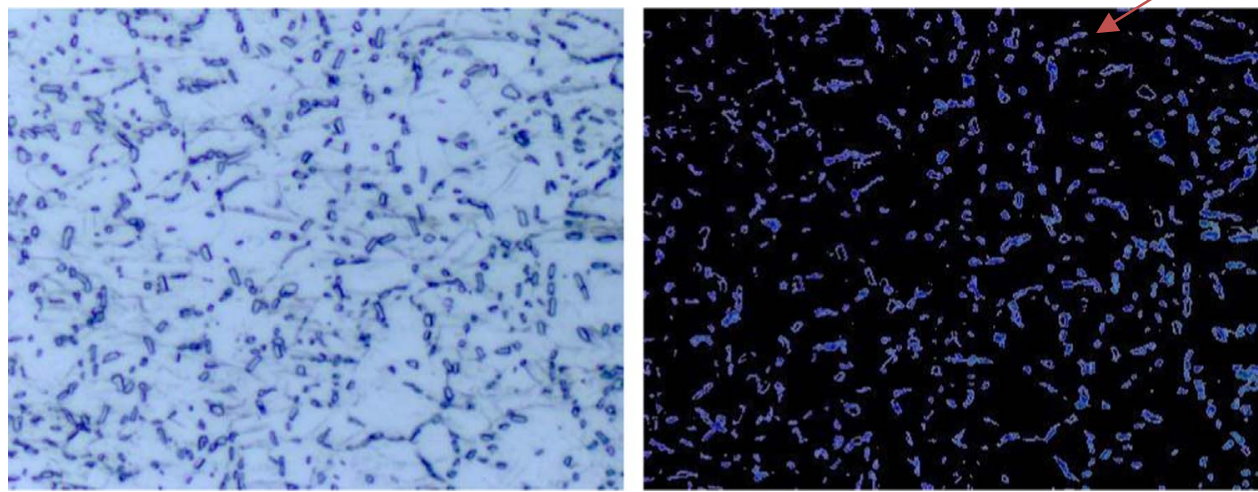

Fig. 11. Delta phase fraction determined from the microstructural observations at the temperature of $600{ }^{\circ} \mathrm{C}$ and $1 \mathrm{~s}^{-1}$ strain rate, utilising Image $\mathrm{J}$ software.
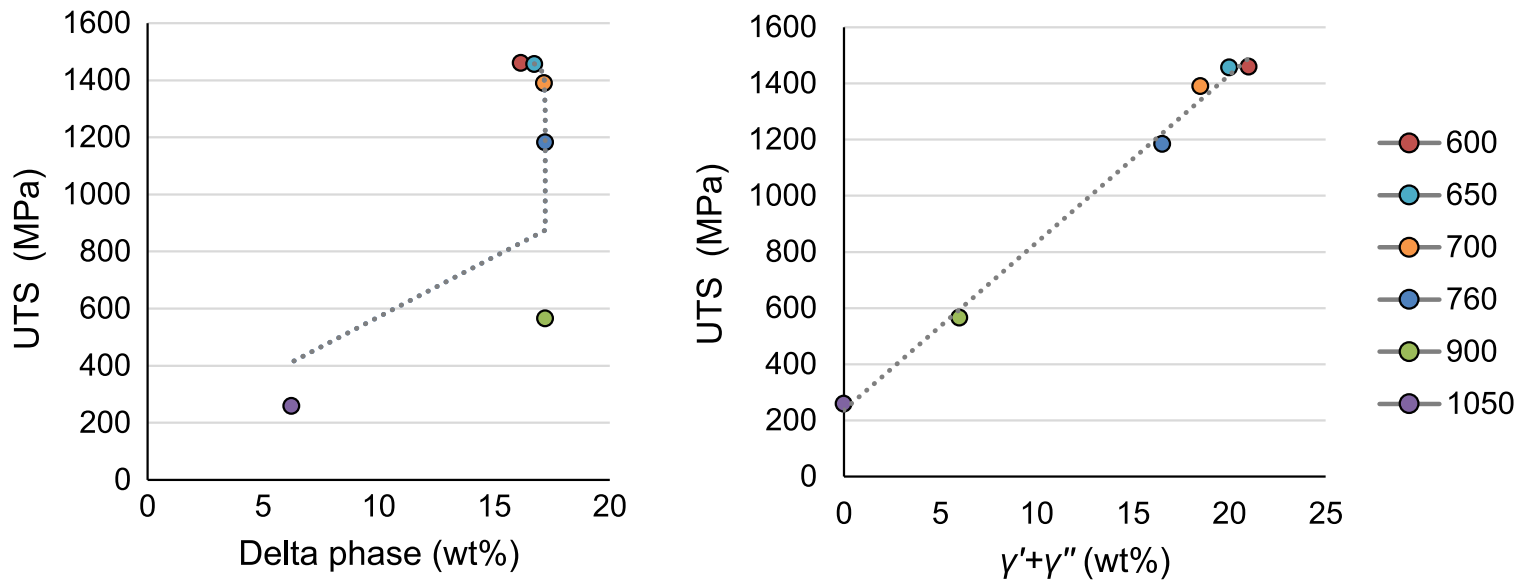

Fig. 12. Influence of the secondary phases on the mechanical properties of the Inconel 718 at the strain rate of $1 \mathrm{~s}^{-1}$.

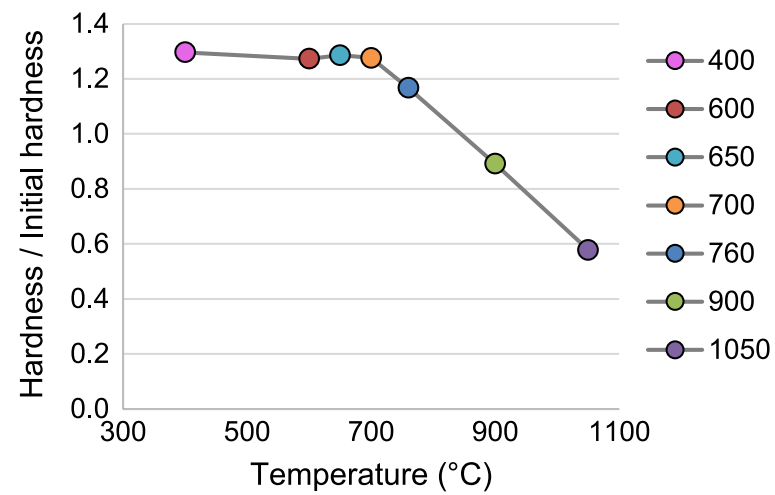

Fig. 13. Influence of the temperature on the stress and the microhardness values of the Inconel 718 when compressed at the strain rate of $1 \mathrm{~s}^{-1}$.

Table 5

Johnson Cook model parameters for the characterized Inconel 718

\begin{tabular}{llllll}
\hline & $A(\mathrm{MPa})$ & $B(\mathrm{MPa})$ & $n$ & $m$ & $C$ \\
\hline Conventional JC model & 1377 & 1243.5 & 0.6767 & 1.29 & 0.0045 \\
\hline
\end{tabular}

curve in Fig. 15. It can be seen that Lurdos (2008) model [22] offers the best stress prediction for the whole strain range.

Therefore, Lurdos model (2) has been chosen to represent the strain hardening-softening term $\left(\sigma_{\varepsilon}\right)$ on the proposed material beha-

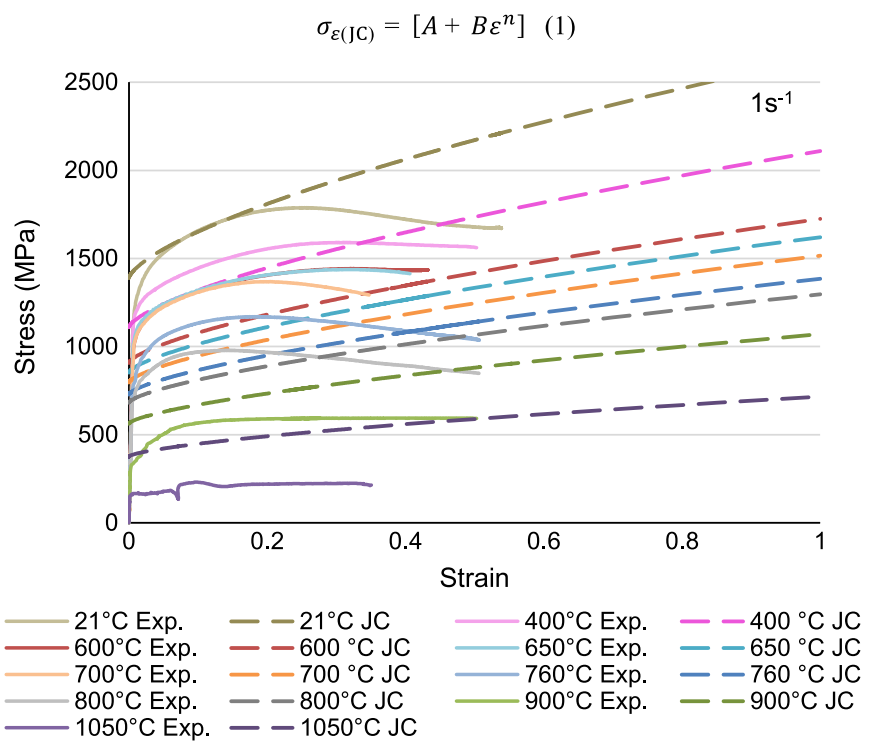

Fig. 14. Comparisons between the measured and predicted results with the conventional JC model in Inconel 718 superalloy. Influence of the temperature $\left(\dot{\varepsilon}=1 \mathrm{~s}^{-1}\right)$.

viour model. In Lurdos model [22] stress is modeled through five model parameters $\sigma_{\mathrm{s}}, \sigma_{0}, r, A, n$, that vary as a function of the temperature and the strain rate, where $\sigma_{0}$ is the yield stress and $\sigma_{\mathrm{s}}$ the saturation stress. For the proposed model, model parameters have been identified 


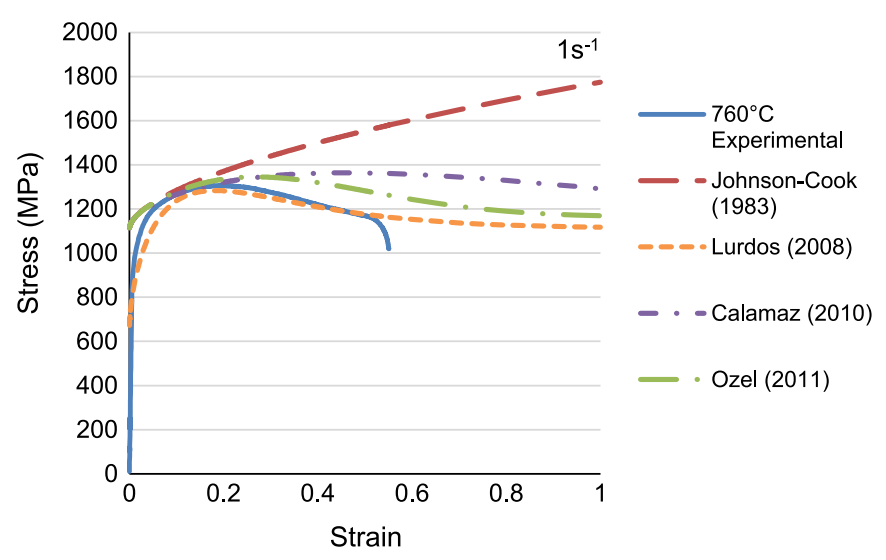

Fig. 15. Comparison between the reference experimental curve, and the curves predicted by common constitutive models found in literature.

Table 6

Model parameters identified for the Inconel 718 to consider the strain hardening/ softening in the proposed model.

\begin{tabular}{llllll}
\hline & $\sigma_{0}(\mathrm{MPa})$ & $\sigma_{\mathrm{s}}(\mathrm{MPa})$ & $\mathrm{A}$ & $\mathrm{n}$ & $\mathrm{r}$ \\
\hline Proposed SH term, $\sigma_{\varepsilon}$ & 1388 & 1565 & 1600 & 0.6767 & 3 \\
\hline
\end{tabular}

from the uniaxial compression tests at the reference temperature and strain rate set at $21^{\circ} \mathrm{C}$ and $1 \mathrm{~s}^{-1}$ respectively (Table 6).

$\sigma_{\varepsilon}=\sigma_{\mathrm{s}}+\left(\sigma_{0}-\sigma_{\mathrm{s}}+A \varepsilon^{n}\right) \exp (-r \varepsilon)$

\subsection{Thermal-softening}

Concerning the thermal softening, Johnson-Cook material model being a decoupled model, could be a valid model to represent the temperature sensitivity of the Inconel 718. Experimentally, the decrease in the flow stress as a result of the temperature increase was observed at the different strain rates tested (Fig. 3, Fig. 5). Therefore, the thermal softening effect could be considered as an independent
Table 7

Modified Johnson-Cook thermal softening term (3) model parameters for the characterized Inconel 718.

\begin{tabular}{llll}
\hline & & $\boldsymbol{T}_{\mathbf{0}}$ & $\boldsymbol{m}$ \\
\hline Modified JC model TS term, $\sigma_{T}$ & $<700^{\circ} \mathrm{C}$ & 21 & 2 \\
& $\geq 700^{\circ} \mathrm{C}$ & 700 & $0.0016^{*} \mathrm{~T}+2.0031$ \\
\hline
\end{tabular}

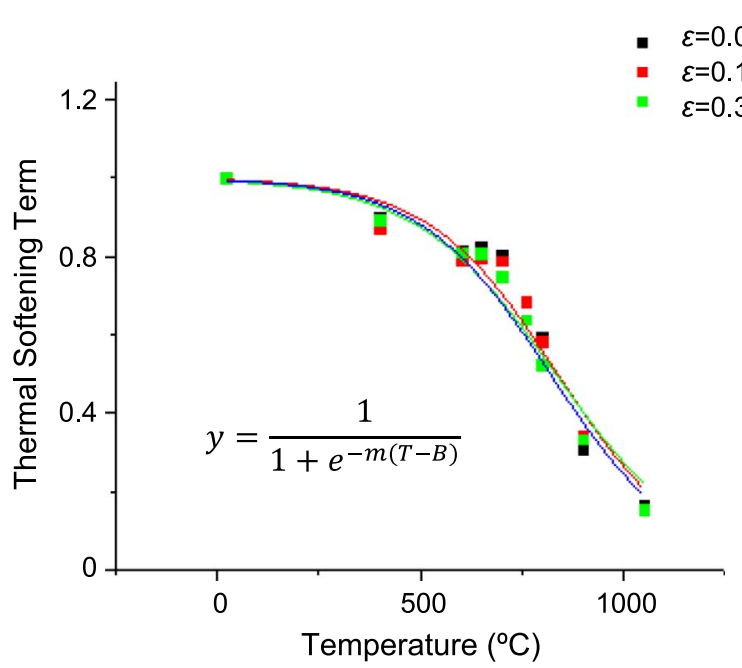

Fig. 17. Proposed Thermal Softening Term for the characterized Inconel 718.

Table 8

Modified thermal softening term model parameters for the characterized Inconel 718.

\begin{tabular}{lll}
\hline & $\boldsymbol{m}$ & $\boldsymbol{B}$ \\
\hline Proposed Thermal Softening term, $\sigma_{T}$ & 0.00663 & 832.27 \\
\hline
\end{tabular}

factor that does not show coupling with the strain rate for the material behaviour model. However, in Fig. 14 it can be seen that with the conventional Johnson-Cook model (3) stress decreases linearly with the temperature rise related to the $m$ parameter. This approximation
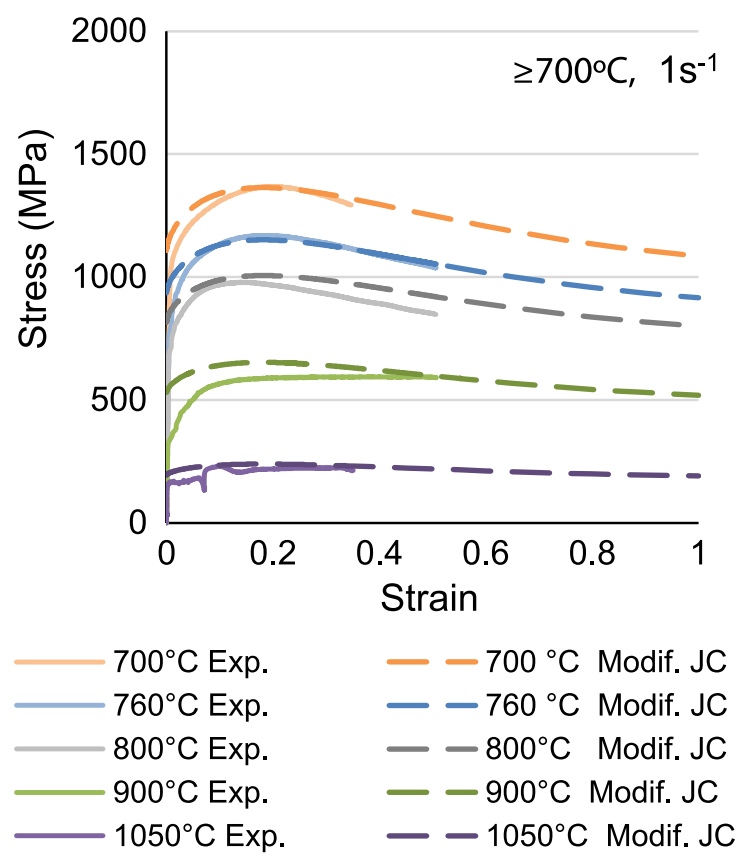

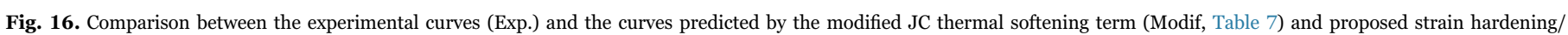
softening term (Table 6). 


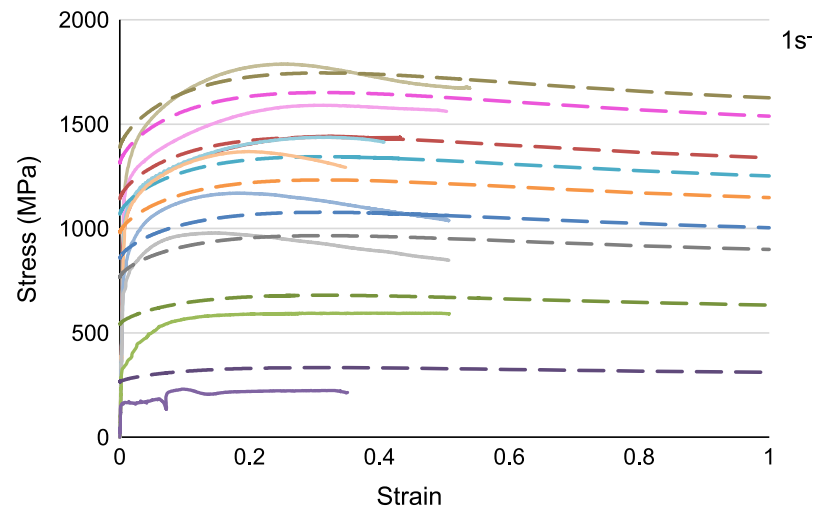

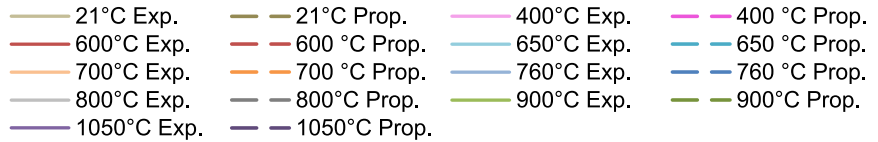

Fig. 18. Comparisons between the measured (Exp.) and predicted results with the proposed thermal softening term (Prop.) in Inconel 718 superalloy. Influence of the temperature $\left(\dot{\varepsilon}=1 \mathrm{~s}^{-1}\right)$.

highly sub estimates the mechanical properties of the Inconel 718 below the temperature of $900{ }^{\circ} \mathrm{C}$, while it overestimates the stress above this temperature (Fig. 14).

$\sigma_{T(\mathrm{JC})}=\left[1-\left(\frac{T-T_{0}}{T_{\mathrm{m}}-T_{0}}\right)^{m}\right]$

Experimental tests made clear that Inconel 718 showed a very different behavior above and below the critical temperature of $700{ }^{\circ} \mathrm{C}$ (Fig. 4). Below this temperature, Inconel 718 was not that sensitive to the temperature increase, the mechanical properties decreased on a $20 \%$ in the temperature range between 21 and $700{ }^{\circ} \mathrm{C}$ (Fig. 3). Above the temperature of $700{ }^{\circ} \mathrm{C}$ on the other hand, the decrease in the mechanical properties with the temperature increase was drastical (Fig. 4). Therefore, below the temperature of $700{ }^{\circ} \mathrm{C}$ the thermal softening in Inconel 718 could be successfully predicted (Fig. 16) by a constant Johnson-Cook temperature sensitivity parameter $m$. Above this temperature on the other hand, $m$ parameter should vary as a function of the temperature (Table 7 ).
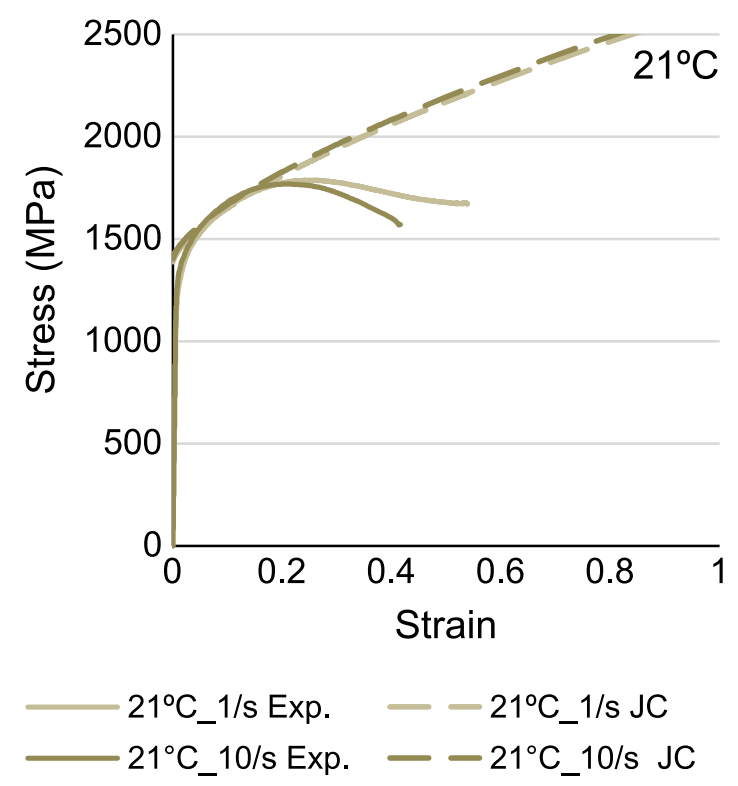

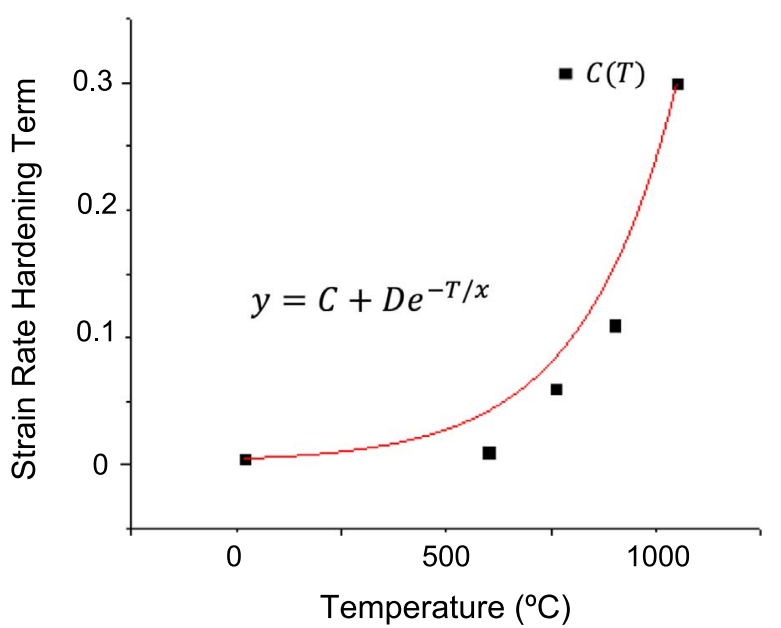

Fig. 20. Proposed Strain Rate Hardening Term for the characterized Inconel 718.

Table 9

Modified strain rate hardening term model parameters for the characterized Inconel 718.

\begin{tabular}{llll}
\hline & $\boldsymbol{x}$ & $\boldsymbol{C}$ & $\boldsymbol{D}$ \\
\hline Proposed Strain Rate Hardening term, $\sigma_{\dot{\varepsilon}}$ & 1110 & 0.39 & -0.67
\end{tabular}

However, in order to increase operability in FEM simulations, it would be more desirable to have a unique thermal softening term that could describe the thermal softening of the Inconel 718 for all temperature range $\left(21-1050{ }^{\circ} \mathrm{C}\right)$. To consider the thermal softening phenomena as nonlinear, an exponential term is proposed (Figs. 17, 4).

$\sigma_{T}=\frac{1}{1+e^{-m(T-B)}}$

Temperature sensitivity parameters $m$ and $B$ (Table 7, Table 8) have been identified from the quasi-static tests at the reference strain rate $1 \mathrm{~s}^{-1}$ and temperatures ranging from $21^{\circ} \mathrm{C}$ to $1050^{\circ} \mathrm{C}$. In Fig. 18 it can be seen, that even if the proposed thermal softening term (4) slightly aggravates the predictions made with the modified JC term (Figs. 16,
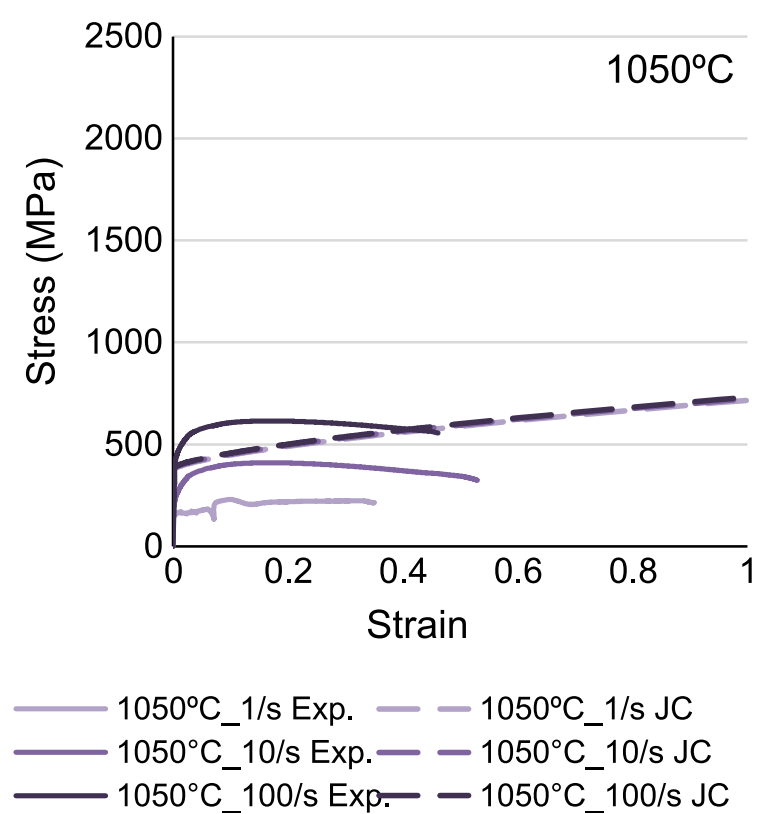

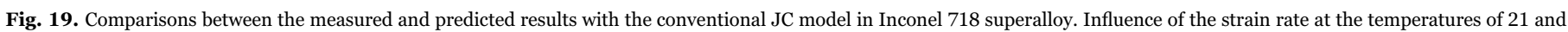
$1050^{\circ} \mathrm{C}$. 

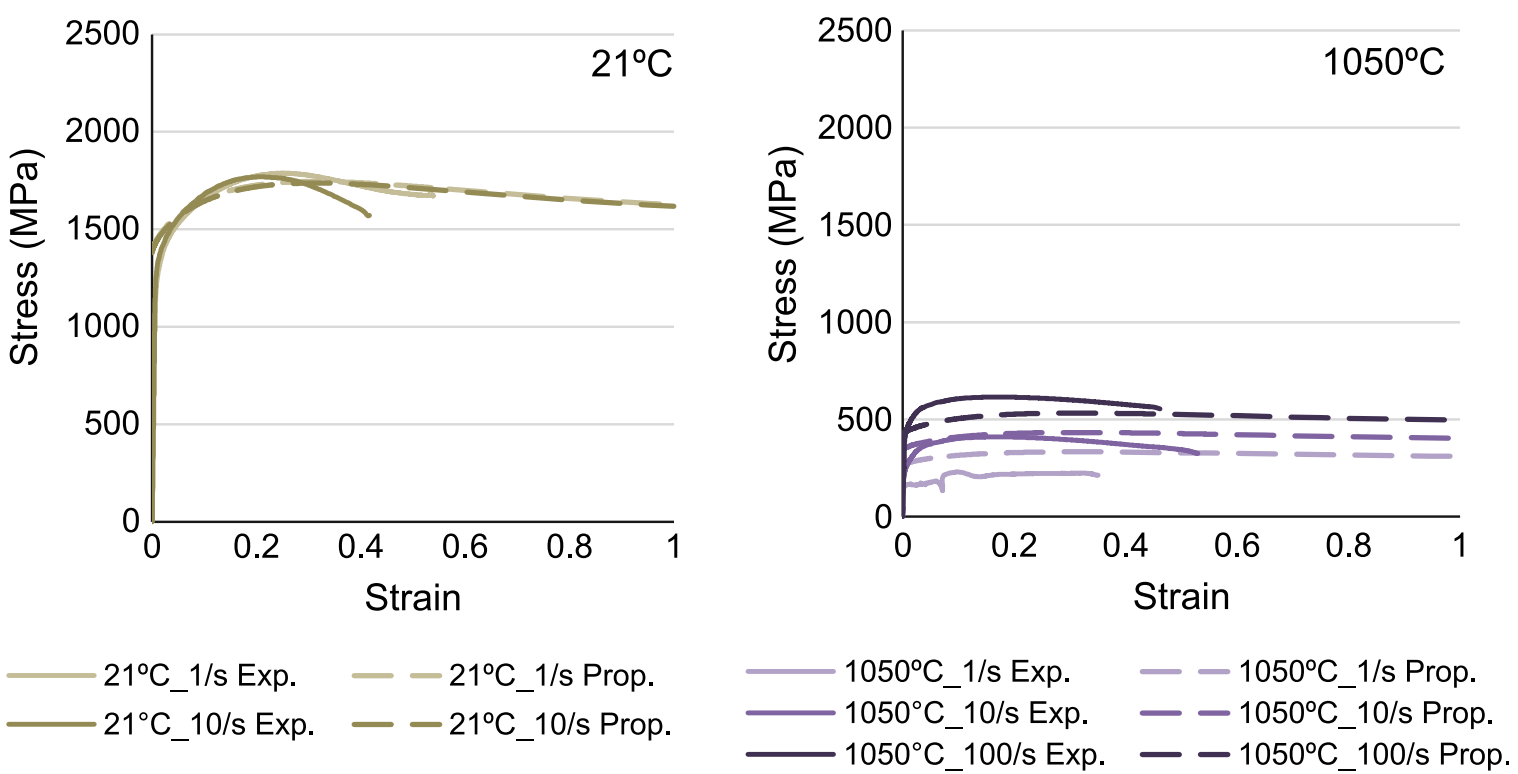

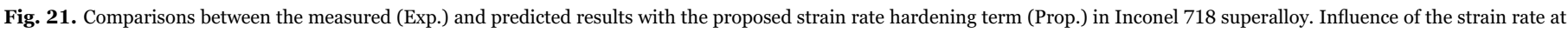
the temperatures of 21 and $1050{ }^{\circ} \mathrm{C}$.

Table 10

Formulation of the proposed coupled constitutive law.

\begin{tabular}{|c|c|}
\hline Proposed model & $\sigma=\sigma_{\varepsilon}(\varepsilon) \cdot \sigma_{T}(T) \cdot \sigma_{\dot{\varepsilon}}(\dot{\varepsilon}, T)$ \\
\hline $\begin{array}{l}\text { (i) Strain hardening/ } \\
\text { softening }\end{array}$ & $\sigma_{\varepsilon}(\varepsilon)=\sigma_{s}+\left(\sigma_{0}-\sigma_{s}+A \varepsilon^{n}\right) \exp (-r \varepsilon)$ \\
\hline (i) Thermal softening & $\sigma_{T}(T)=\frac{1}{1+e^{-m(T-B)}}$ \\
\hline (i) Strain rate hardening & $\sigma_{\dot{\varepsilon}}(\dot{\varepsilon}, T)=\left[1+C(T) \ln \left(\frac{\dot{\varepsilon}}{\dot{\varepsilon}_{0}}\right)\right]=\left[1+\left(C+D e^{-T / x}\right) \quad \ln \left(\frac{\dot{\varepsilon}}{\dot{\varepsilon}_{0}}\right)\right]$ \\
\hline
\end{tabular}

3), this approach would be more appropriate from the operability point of view.

The proposed thermal softening (TS) term (4), highly improves the JC thermal softening term (3) predictions. On the plastic region up to the strain level of 0.5 (available experimental data) the proposed model reduces the average error from $25 \%$ with the $\mathrm{JC}$ model to less than the $10 \%$ at the temperature range between $21-800{ }^{\circ} \mathrm{C}$. This average error slightly increases with further increasing the temperature with both TS terms $(3,4)$, but still remains much lower with the proposed TS term. The average error was reduced from $50 \%$ to $15 \%$ at the temperature of $900{ }^{\circ} \mathrm{C}$ and from $130 \%$ to $50 \%$ at the temperature of $1050{ }^{\circ} \mathrm{C}$ by the modification introduced in the proposed thermal softening term.

\subsection{Strain rate hardening}

As stated before, Johnson-Cook model is an uncoupled model that neglects the coupling between the temperature and the strain-rate (5) known to occur experimentally (Fig. 5). From the uniaxial compression tests, carried out at different temperatures $\left(21-1050{ }^{\circ} \mathrm{C}\right)$ and strain rates $\left(10^{\circ}-10^{2} \mathrm{~s}^{-1}\right)$ it was concluded that the influence of strain rate on flow stress of the Inconel 718 is temperature dependent. At the low temperature domain $\left(<700{ }^{\circ} \mathrm{C}\right)$, the influence of the strain rate on the material strength was found to be practically negligible but as the temperature increased, the material behaved in a more viscous manner (Fig. 5). If the strain rate sensitivity parameter (C) was identified in the conventional way (Table 5), through dynamic testing at the reference temperature $\left(21^{\circ} \mathrm{C}\right)$ and different strain rates $\left(10^{\circ}-10^{2} \mathrm{~s}^{-1}\right)$ the value of $C$ would be almost 0 and the influence of the strain rate hardening in Inconel 718 would be neglected. Nevertheless, this would not meet the strain rate hardening behaviour seen experimentally at high temperatures (Fig. 19), which are closer to a machining environment.
Therefore, the coupling between the temperature and the strain rate should be taken into account when proposing a material behaviour model for machining FEM simulations with Inconel 718 superalloy.

$\sigma_{\dot{\varepsilon}(J C)}=\left[1+C \ln \left(\frac{\dot{\varepsilon}}{\dot{\varepsilon}_{0}}\right)\right]$

As shown in Fig. 20, the Johnson-Cook strain-rate sensitivity parameter $C$ increased exponentially with increasing temperature. Therefore, to consider the coupling between the temperature and the strain rate an exponential function is proposed (Figs. 20, 6). Strain rate sensitivity parameters $x, C$ and D (Table 9 ) have been identified from all the temperature-strain rate testing configurations (Table 3).

$\sigma_{\dot{\varepsilon}}=\left[1+C(T) \ln \left(\frac{\dot{\varepsilon}}{\dot{\varepsilon}_{0}}\right)\right]=\left[1+\left(C+D e^{-T / x}\right) \ln \left(\frac{\dot{\varepsilon}}{\dot{\varepsilon}_{0}}\right)\right]$

In Fig. 21 it can be seen that the proposed strain rate hardening (SRH) term (6), highly improves the JC strain rate hardening (SRH) term (5) predictions (Fig. 19). On the plastic region up to the strain level of 0.5 (available experimental data) the proposed model reduces the average error from $40 \%$ with the JC model to less than the $15 \%$. (Table 10 )

Finally, to sum up, the new material model proposed to represent the material behaviour of the Inconel 718 at temperatures and strain rate ranges close to those found in machining is summarized in the following table:

\section{Conclusions}

In this work, an experimental study of the rheology of the Inconel 718 was conducted over a wide range of temperatures and strain rates characteristic of machining processes. Two different behaviour domains were identified as a function of the temperature, above and below the critical temperature set at $700{ }^{\circ} \mathrm{C}$. A detailed description of each domain was given relating the flow stress curves, with the material microstructure and microhardness measurements.

Based on this experimental data, a coupled empirical model was established to describe the particular behaviour of nickel based superalloys at elevated temperatures and high strain rates. Based on the conventional Johnson-Cook model, a coupled empirical model that introduces strain softening as well as the coupling between the temperature and the strain rate was developed for machining FEM simulations with Inconel 718 superalloy. 


\section{Acknowledgements}

This paper is funded from the projects CRINCOPLUS (UE2013-08), ENOVAL (FP7-604999) and DESAFIO II (RTC-2014-1861-4).

\section{References}

[1] R.C. Reed, The superalloys: fundamentals and applications, Cambridge University Press, 2008.

[2] R. Jeniski Jr, R. Kennedy, Development of ATI Allvac ${ }^{\circledR} 718$ Plus $^{\circledR}$ alloy and applications, Stress 807 (2006) 15.

[3] T.M. Pollock, S. Tin, P. Martin, Nickel-based superalloys for advanced turbine engines: chemistry, microstructure and properties, J. Propuls. Power 22 (2006) 361-374.

[4] P. Spittle, Gas turbine technology, Phys. Educ. 38 (2003) 504.

[5] D. Furrer, H. Fecht, Ni-based superalloys for turbine discs, JOM J. Miner. Met. Mater. Soc. 51 (1999) 14-17.

[6] E. Ezugwu, Z. Wang, A. Machado, The machinability of nickel-based alloys: a review, J. Mater. Process. Technol. 86 (1998) 1-16.

[7] D. Umbrello, The effects of cutting conditions on surface integrity in machining Inconel 718 alloy, Key Eng. Mater. 554-557 (2013) 2093-2100.

[8] D. Zhu, X. Zhang, H. Ding, Tool wear characteristics in machining of nickel-based superalloys, Int. J. Mach. Tools Manuf. (2012).

[9] P. Arrazola, T. Özel, D. Umbrello, M. Davies, I. Jawahir, Recent advances in modelling of metal machining processes, CIRP Ann. Manuf. Technol. 62 (2013) 695-718.

[10] T. Ozel, I. Llanos, J. Soriano, P-J. Arrazola, 3D finite element modelling of chip formation process for machining Inconel 718: comparison of FE software predictions, Machining Science and Technology 15 (1) (2011) 21-46.

[11] B. Shi, H. Attia, N. Tounsi, Identification of material constitutive laws for machining-Part I: an analytical model describing the stress, strain, strain rate, and temperature fields in the primary shear zone in orthogonal metal cutting, J. Manuf. Sci. Eng. 132 (2010) 051008.

[12] X. Wang, C. Huang, B. Zou, H. Liu, H. Zhu, J. Wang, Dynamic behavior and a modified Johnson-Cook constitutive model of Inconel 718 at high strain rate and elevated temperature, Mater. Sci. Eng. A 580 (2013) 385-390.

[13] G. Germain, A. Morel, T. Braham-Bouchnak, Identification of material constitutive laws representative of machining conditions for two titanium alloys: $\mathrm{Ti}_{6} \mathrm{Al}_{4} \mathrm{~V}$ and Ti555-3, J. Eng. Mater. Technol. 135 (2013) 031002.

[14] A. Hor, F. Morel, J. Lebrun, G. Germain, Modelling, identification and application of phenomenological constitutive laws over a large strain rate and temperature range, Mech. Mater. 64 (2013) 91-110.

[15] S. Mitsche, C. Sommitsch, D. Huber, M. Stockinger, P. Poelt, Assessment of dynamic softening mechanisms in Allvac ${ }^{\otimes} 718$ Plus $^{\text {TM }}$ by EBSD analysis, Mater. Sci. Eng. A 528 (2011) 3754-3760.

[16] S. Soo, D. Aspinwall, R. Dewes, 3D FE modelling of the cutting of Inconel 718, J. Mater. Process. Technol. 150 (2004) 116-123.

[17] H. Yuan, W. Liu, Effect of the $\delta$ phase on the hot deformation behavior of Inconel 718, Mater. Sci. Eng. A 408 (2005) 281-289.

[18] J. Si, X. Liao, L. Xie, K. Lin, Flow Behavior and Constitutive Modeling of Deltaprocessed Inconel 718 alloy, J. Iron Steel Res. Int. 22 (2015) 837-845.

[19] Y. Wang, W. Shao, L. Zhen, L. Yang, X. Zhang, Flow behavior and microstructures of superalloy 718 during high temperature deformation, Mater. Sci. Eng. A 497 (2008) 479-486.

[20] G.R.Johnson, W.H.CookA constitutive model and data for metals subjected to large strains, high strain rates and high temperatures, in: Proceedings of the 7th
International Symposium on Ballistics,1983, pp. 541-547.

[21] M. Calamaz, D. Coupard, F. Girot, Numerical simulation of titanium alloy dry machining with a strain softening constitutive law, Mach. Sci. Technol. 14 (2010) 244-257.

[22] O. Lurdos, F. Montheillet, G. Damamme, Empirical and physically based flow rules relevant to high speed processing of 304L steel, Int. J. Mater. Form. 1 (2008) $1431-1434$.

[23] Y. Lin, X. Chen, G. Liu, A modified Johnson-Cook model for tensile behaviors of typical high-strength alloy steel, Mater. Sci. Eng. A 527 (2010) 6980-6986.

[24] A. He, G. Xie, H. Zhang, X. Wang, A comparative study on Johnson-Cook, modified Johnson-Cook and Arrhenius-type constitutive models to predict the high temperature flow stress in 20CrMo alloy steel, Mater. Des. 52 (2013) 677-685.

[25] L. Chen, G. Zhao, J. Yu, Hot deformation behavior and constitutive modeling of homogenized 6026 aluminum alloy, Mater. Des. 74 (2015) 25-35.

[26] M. Sima, T. Özel, Modified material constitutive models for serrated chip formation simulations and experimental validation in machining of titanium alloy Ti-6Al-4V, Int. J. Mach. Tools Manuf. 50 (2010) 943-960.

[27] E. Voce, The relationship between stress and strain for homogeneous deformation, J. Inst. Met 74 (1948) 537-562.

[28] A. Hor, F. Morel, J. Lebrun, G. Germain, An experimental investigation of the behaviour of steels over large temperature and strain rate ranges, Int. J. Mech. Sci. 67 (2013) 108-122.

[29] W.F. Hosford, Mechanical Behavior of Materials, Cambridge University Press, 2010.

[30] N.FangSensitivity analysis of the material flow stress in machining, in: ASME 2003 International Mechanical Engineering Congress and Exposition, 2003, pp. 23-32.

[31] J.J. Jonas, X. Quelennec, L. Jiang, É. Martin, The Avrami kinetics of dynamic recrystallization, Acta Mater. 57 (2009) 2748-2756.

[32] H. Najafi, S. Asgari, Strain hardening mechanisms in aged AEREX350 superalloy, Mater. Sci. Eng. A 398 (2005) 204-208.

[33] D. Zhao, P. Chaudhury, Effect of starting grain size on as-deformed microstructure in high temperature deformation of alloy 718, Superalloys 718 (1994) 625-706.

[34] W.D.CaoSolidification and solid state phase transformation of allvac ${ }^{\oplus} 718$ Plus $^{\mathrm{TM}}$ alloy, in: Proceedings of the Sixth International Special Emphasis Symposium on Superalloys 718, 625, 706 and Derivatives, 2005, pp. 165-177.

[35] R. Kennedy, Allvac ${ }^{\circledast} 718$ Plus $^{\mathrm{TM}}$, Superalloy for the Next Forty Years, Superalloys 718 (2005) 625-706.

[36] S. Hong, W. Chen, T. Wang, A diffraction study of the $\gamma^{\prime \prime}$ phase in INCONEL 718 superalloy, Metall. Mater. Trans. A 32 (2001) 1887-1901.

[37] J.M. Pereira, B.A. Lerch, Effects of heat treatment on the ballistic impact properties of Inconel 718 for jet engine fan containment applications, International Journal of Impact Engineering 25 (8) (2001) 715-733.

[38] E. Uhlmann, M. Graf von der Schulenburg, R. Zettier, Finite element modeling and cutting simulation of Inconel 718, CIRP Annals-Manufacturing Technology 56 (1) (2007) 61-64.

[39] Rainer Sievert, Hans-Dieter Noack, Andreas Hamann, Peter Löwe, K.N. Singh, Georgia Künecke, R. Clos, et al., Simulation der Spansegmentierung beim Hochgeschwindigkeits-zerspanen unter Berücksichtigung duktiler Schädigung, Technische Mechanik 23 (2-4) (2003) 216-233.

[40] J. Olschewski, A. Hamann, M. Bendig, Werkstoffmechanik einer Nickelbasislegierung beim Hochgeschwindigkeitsspanen-Werkstoffverhalten und ModellierungTeil II, Report BAM 201 (2001), 2001.

[41] A.V. Mitrofanov, V.I. Babitsky, V.V. Silberschmidt, Thermomechanical finite element simulations of ultrasonically assisted turning, Computational Materials Science 32 (3) (2005) 463-471.

[42] John Lorentzon, Niklas Järvstråt, B.L. Josefson, Modelling chip formation of alloy 718, Journal of Materials Processing Technology 209 (10) (2009) 4645-4653. 